\title{
New Acylated Phenolic Glycosides with ROS Scavenging Activity from Psidium guajava Leaves
}

Yuanyuan Li, ${ }^{\dagger}$ Dongli Li, ${ }^{\ddagger}$ Qi An, ${ }^{\dagger}$ Hang Ma, ${ }^{\ddagger}{ }^{\S}$ Yu Mu, ${ }^{\dagger}$ Wenjun Qiao, $\|$ Zengguang Zhang, ${ }^{\dagger}$ Jingsheng Zhang, $\|$ Xueshi Huang, ${ }^{*}, \dagger$ and Liya $\mathrm{Li}^{*}, \dagger$

${ }^{\dagger}$ Institute of Microbial Pharmaceuticals, College of Life and Health Sciences, Northeastern University, Shenyang 110819, P. R. China School of Biotechnology and Health Sciences, Wuyi University, Jiangmen 529020, P. R. China

$\S$ Bioactive Botanical Research Laboratory, Department of Biomedical and Pharmaceutical Sciences, College of Pharmacy, University of Rhode Island, Kingston, RI, 02881, United States

॥ Affiliated Hospital of Liaoning University of Traditional Chinese Medicine, Shenyang 110032, P. R. China

*Author to whom correspondence should be addressed

Phone/Fax: 0086-24-83656106; E-mail: huangxs@ mail.neu.edu.cn

Phone/Fax: 0086-24-83656122; E-mail:1yli@mail.neu.edu.cn 
Figure S1. HRESI-MS spectrum of the new compound 1

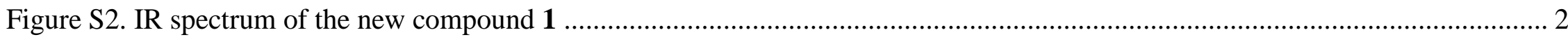

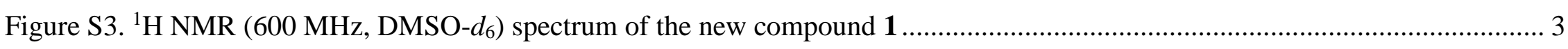

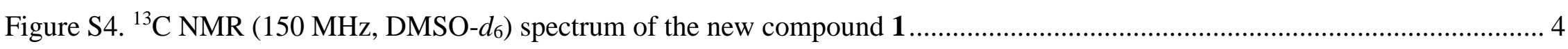

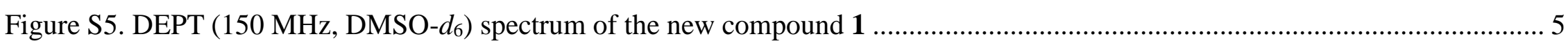

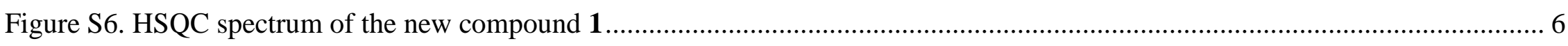

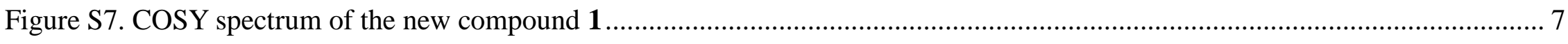

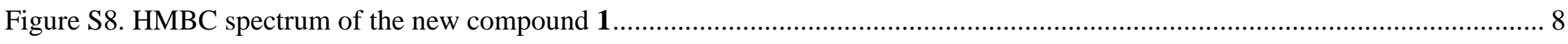

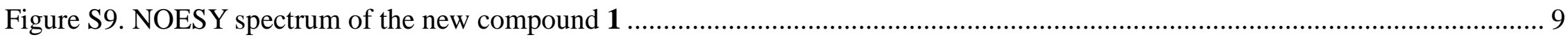

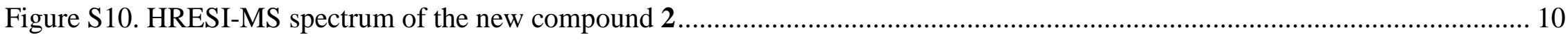

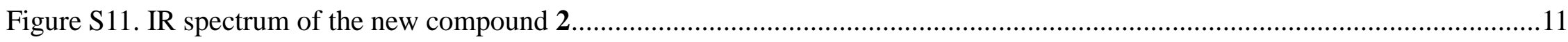

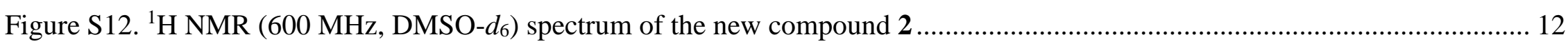

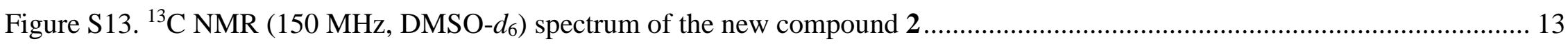

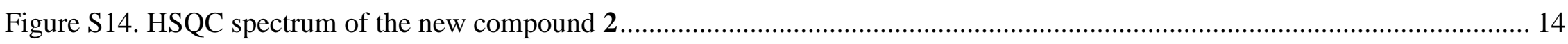

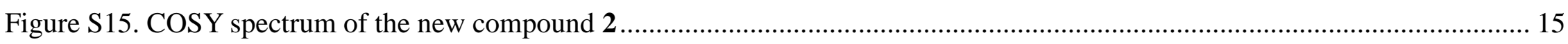

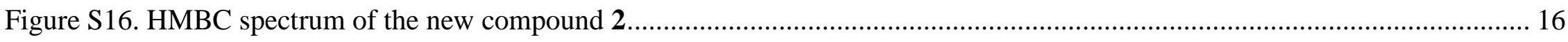

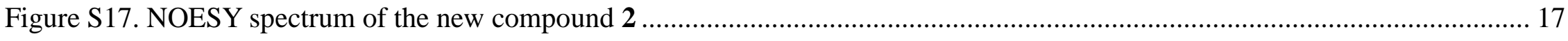

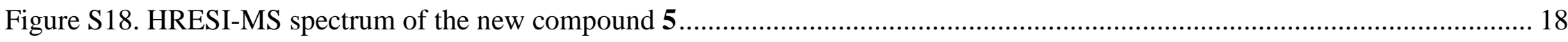


Figure S19. IR spectrum of the new compound 5

Figure S20. ${ }^{1} \mathrm{H}$ NMR (600 MHz, DMSO- $\left.d_{6}\right)$ spectrum of the new compound 5.

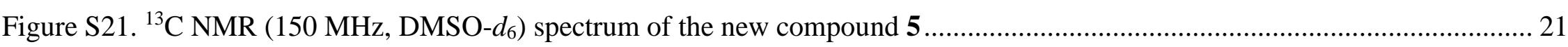

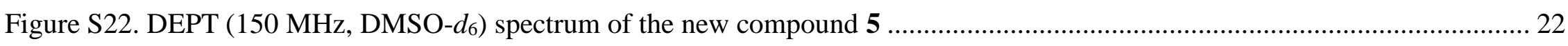

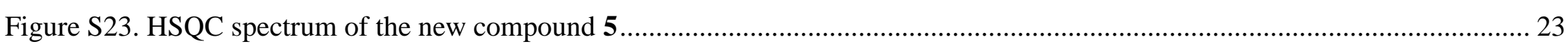

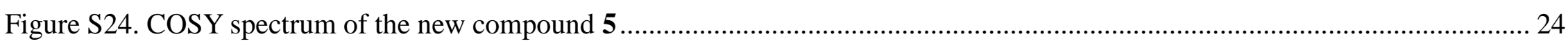

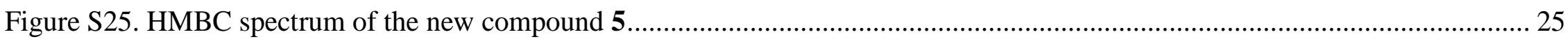

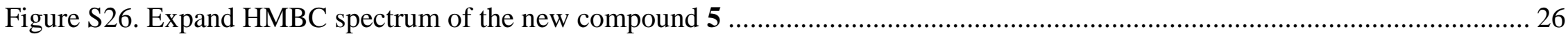

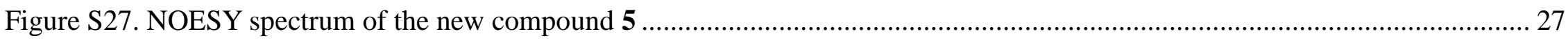

Figure S28. GC analysis of derivatives of standard D-glucose, L-glucose and sugar residue derivative of compound $\mathbf{5}$.................... 28

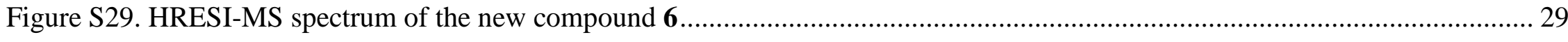

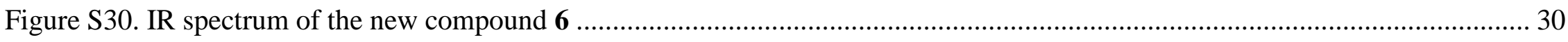

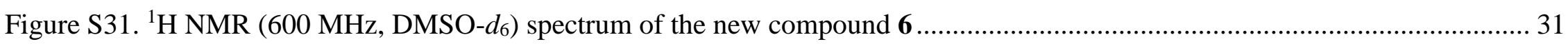

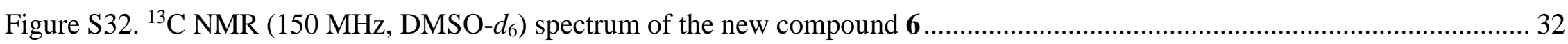

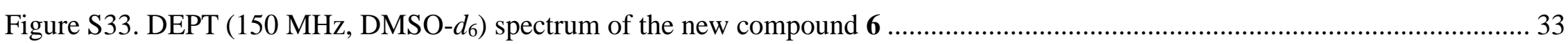

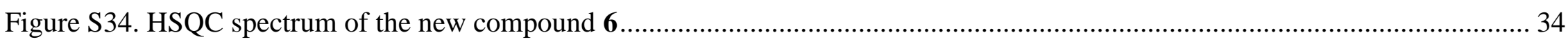

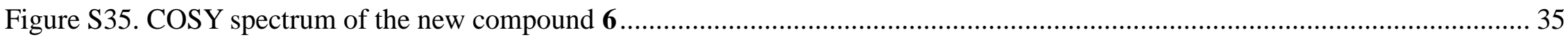

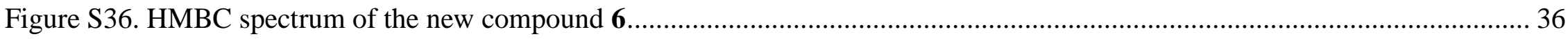


Figure S37. NOESY spectrum of the new compound $\mathbf{6}$

Figure S38. GC analysis of derivatives of standard D-glucose, L-glucose and sugar residue derivative of compound $\mathbf{6} \ldots . . . . . . . . . . . . . . . . .38$

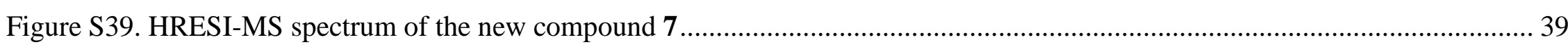

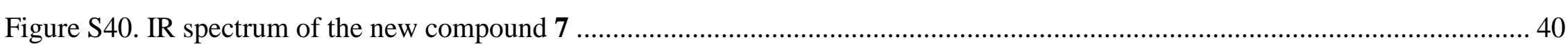

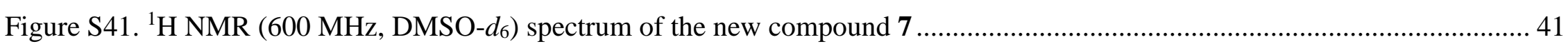

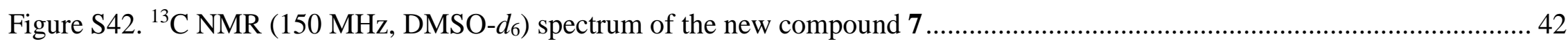

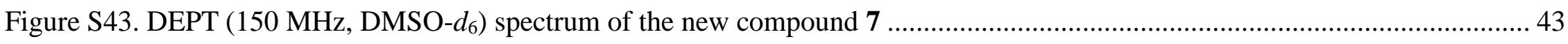

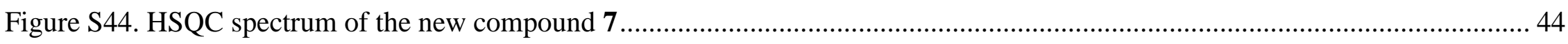

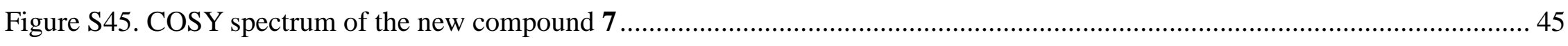

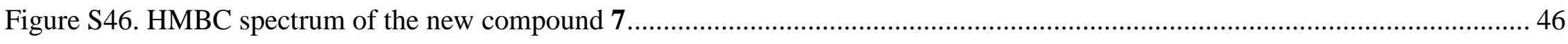

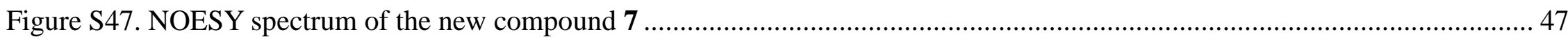

Figure S48. GC analysis of derivatives of standard D-galactose, L-galactose and sugar residue derivative of compound 7................ 48

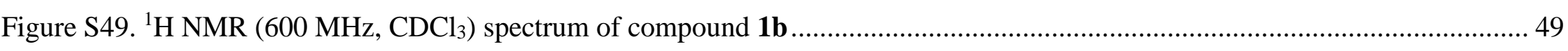

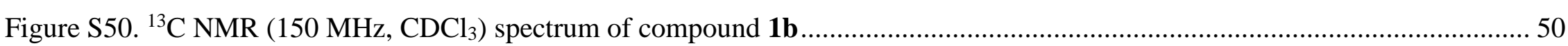

Figure S51. Effect of compounds 1-11 on cell viability of RAW 264.7 macrophages with LPS stimulation.................................... 51

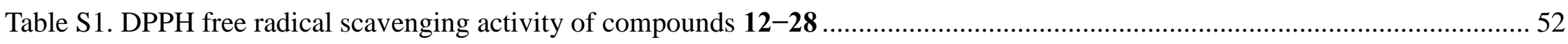

Table S2. ROS scavenging capacity of compounds 1-11 in RAW 264.7 macrophages with LPS stimulation ................................... 53

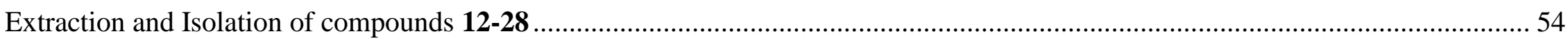





\section{Qualitative Analysis Report}

$\begin{array}{llll}\text { Data Filename } & \text { N-MS-99-NEG.d } & \text { Sample Name } & \text { Sample6 } \\ \text { Sample Type } & \text { Sample } & \text { Position } & \text { P1-A6 } \\ \text { Instrument Name } & \text { Instrument 1 } & \text { User Name } & \\ \text { Acq Method } & \text { default-20170301-neg.m } & \text { Acquired Time } & \text { 3/20/2019 3:59:20 PM } \\ \text { IRM Calibration Status } & \text { Success } & \text { DA Method } & \text { default_Analysis.m }\end{array}$

Comment

Sample Group Info.

User Spectra

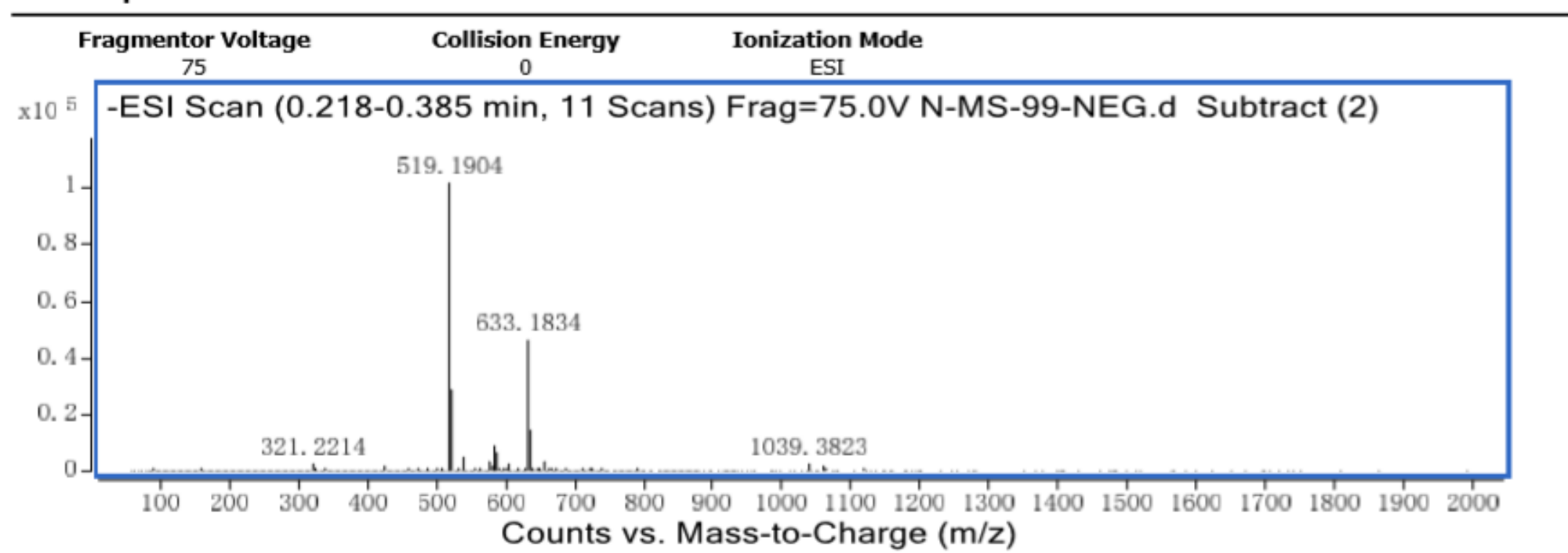

Figure S1. HRESI-MS spectrum of the new compound 1 


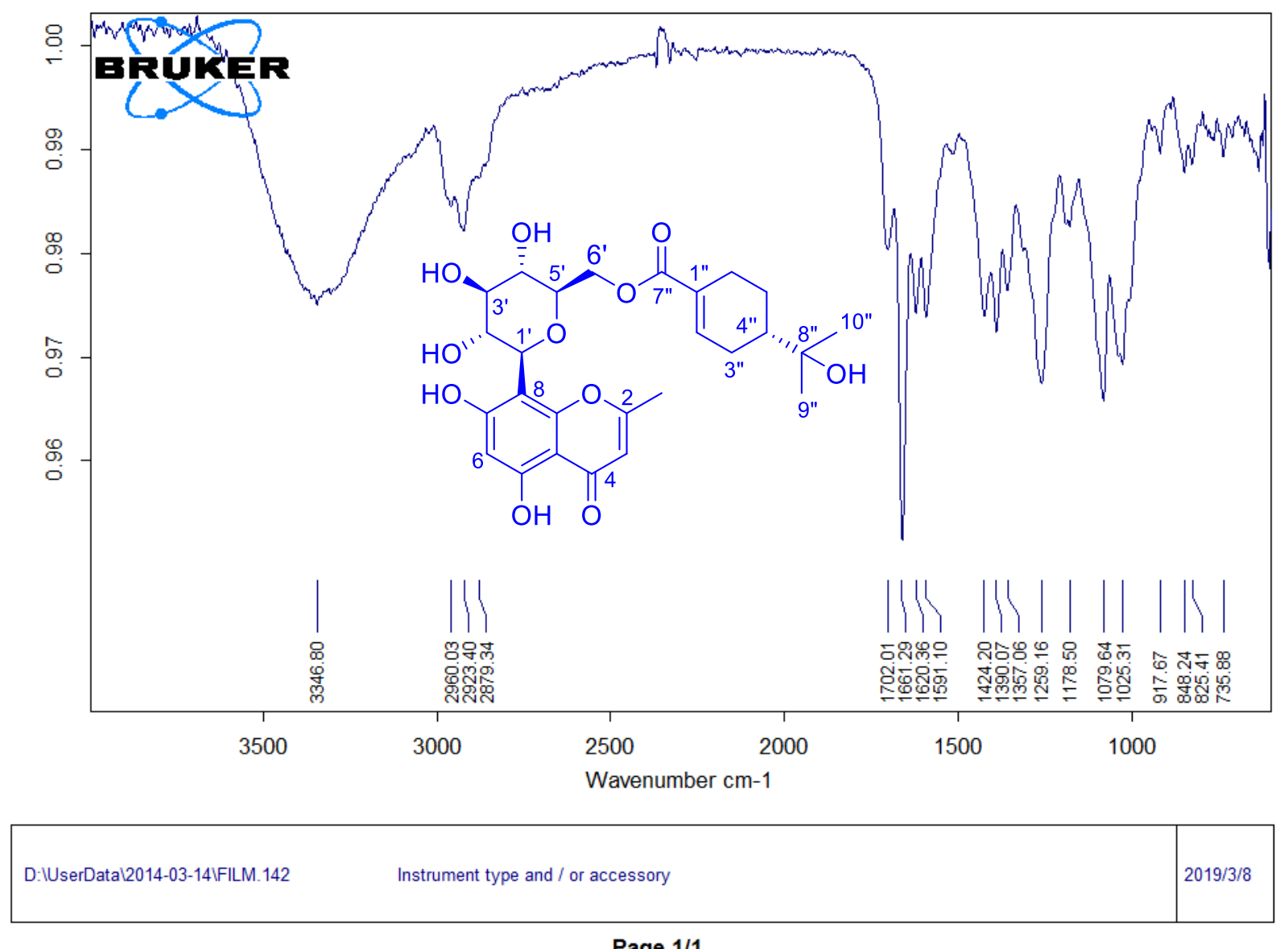

Page 1/1

Figure S2. IR spectrum of the new compound 1 
$\stackrel{8}{\stackrel{3}{3}}$
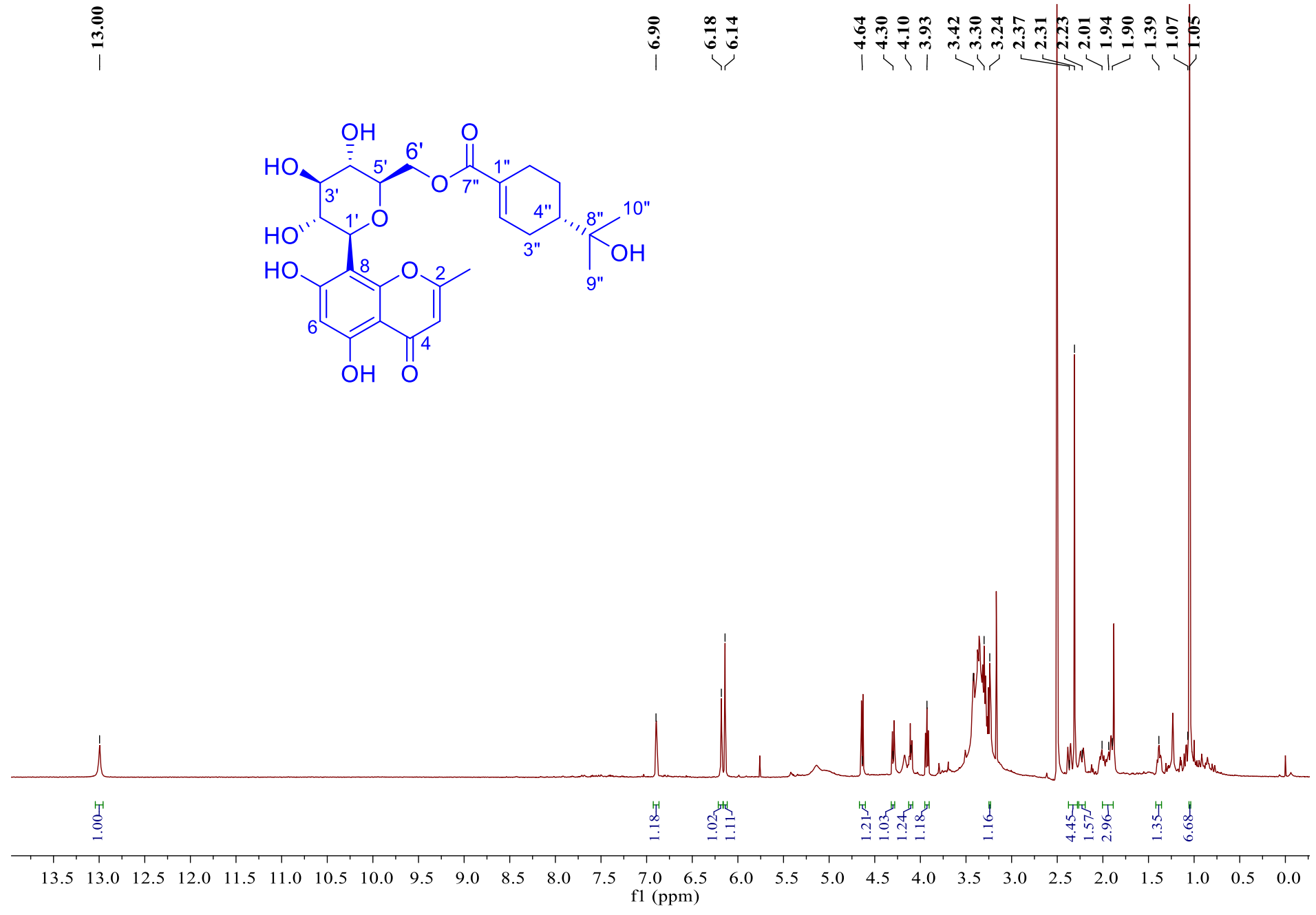

Figure S3. ${ }^{1} \mathrm{H}$ NMR $\left(600 \mathrm{MHz}, \mathrm{DMSO}-d_{6}\right)$ spectrum of the new compound $\mathbf{1}$ 

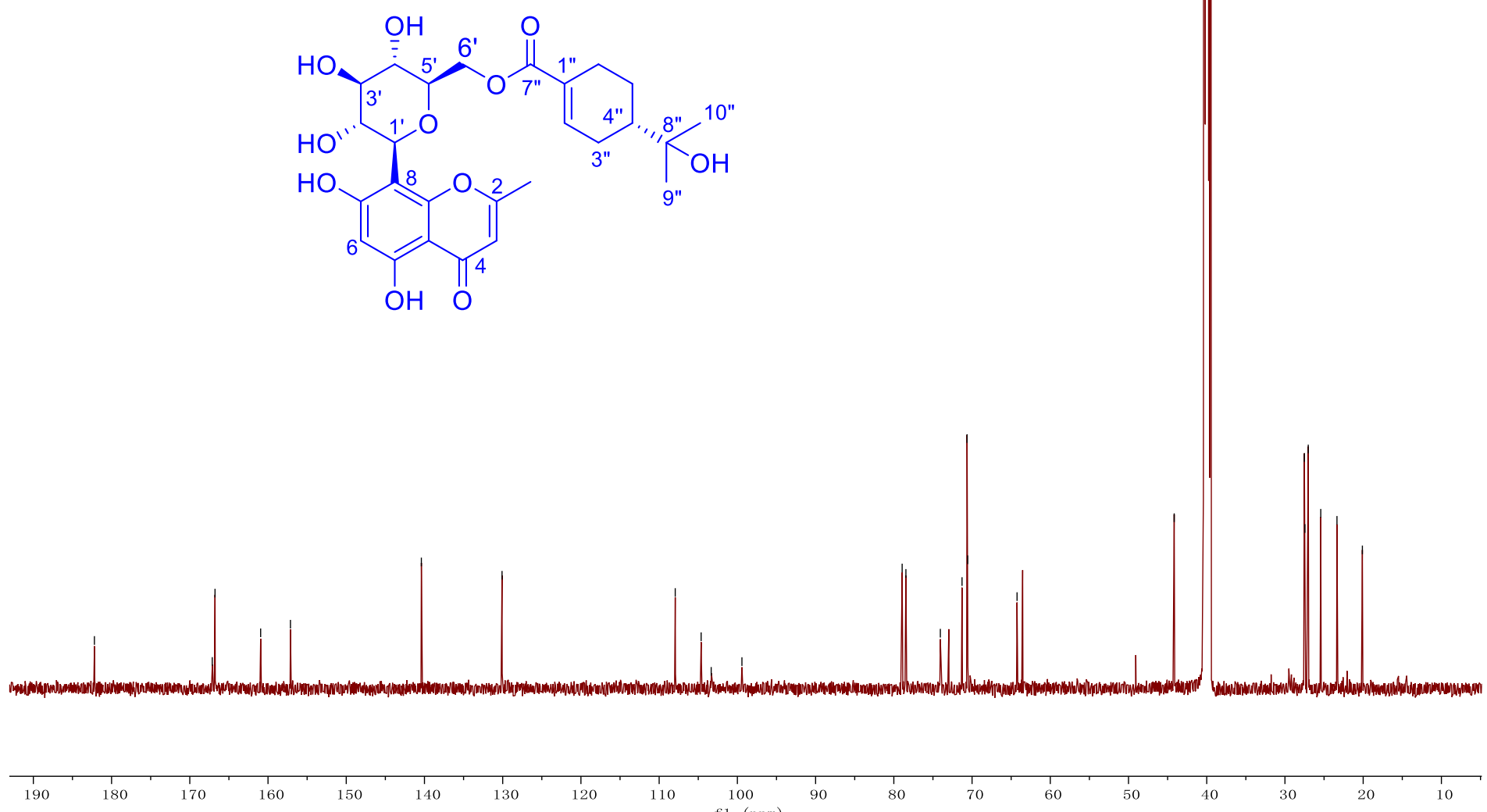

Figure S4. ${ }^{13} \mathrm{C}$ NMR $\left(150 \mathrm{MHz}\right.$, DMSO- $\left.d_{6}\right)$ spectrum of the new compound $\mathbf{1}$ 

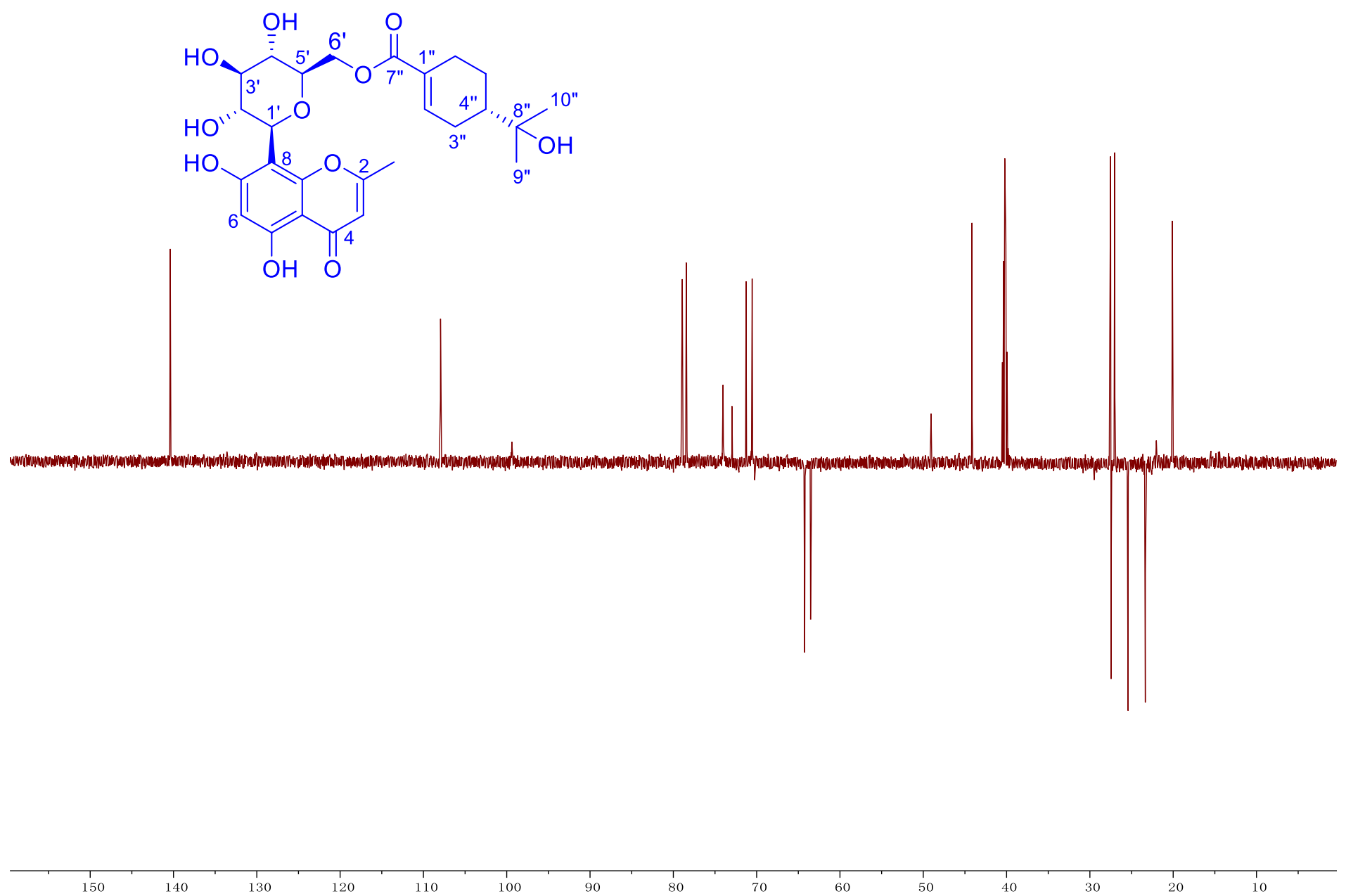

Figure S5. DEPT (150 MHz, DMSO- $\left.d_{6}\right)$ spectrum of the new compound 1 


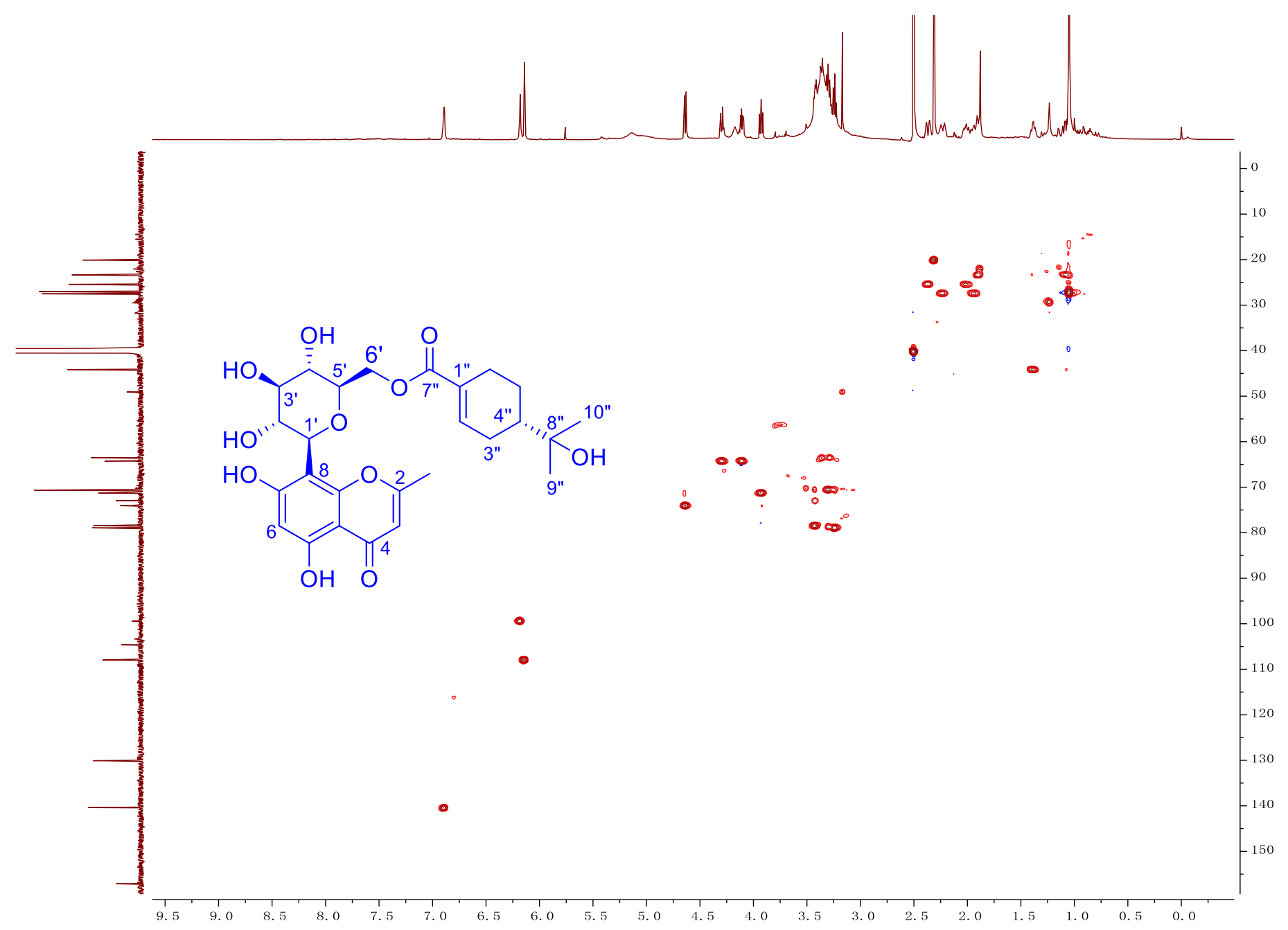

Figure S6. HSQC spectrum of the new compound 1 


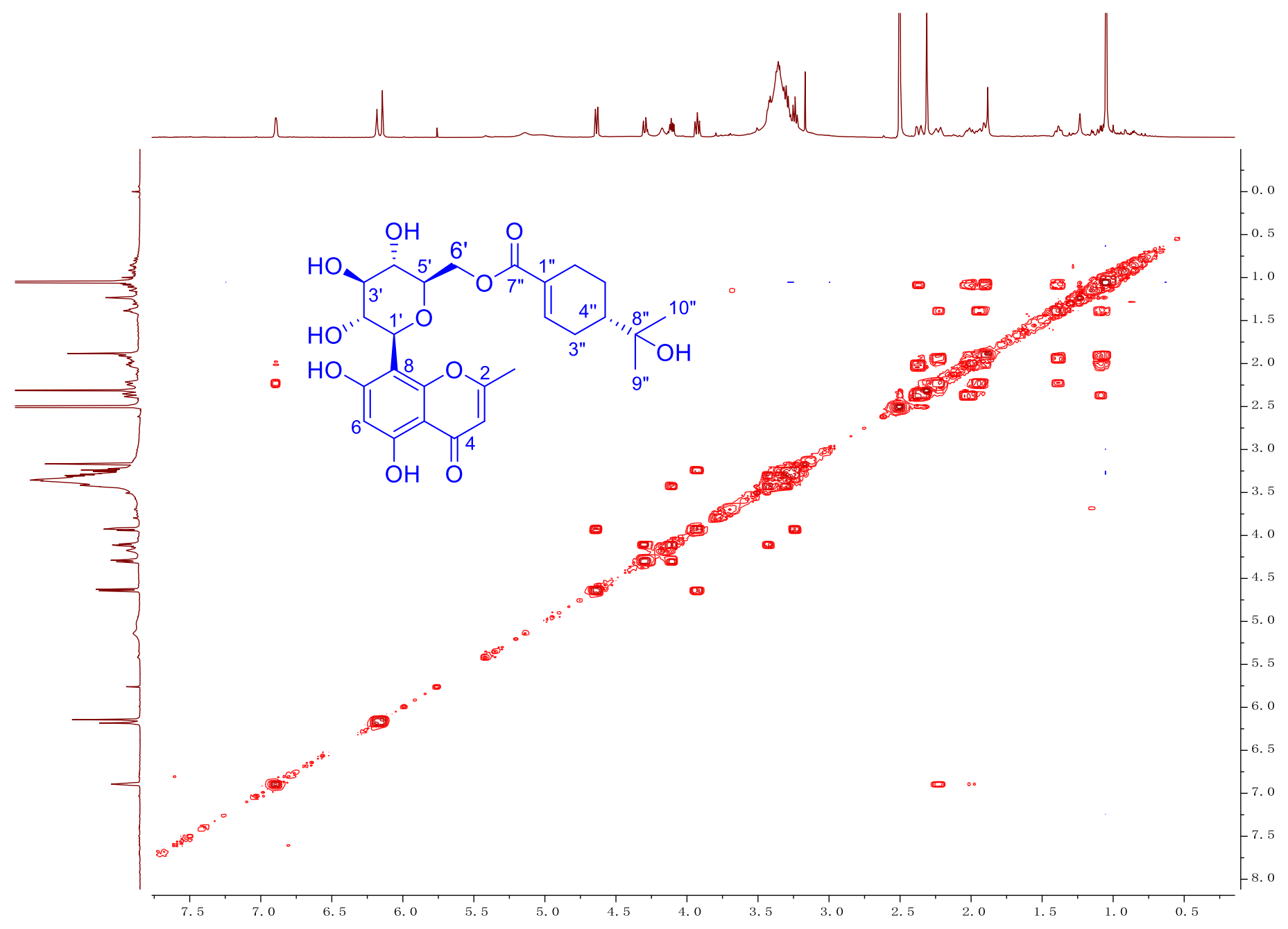

Figure S7. COSY spectrum of the new compound $\mathbf{1}$ 


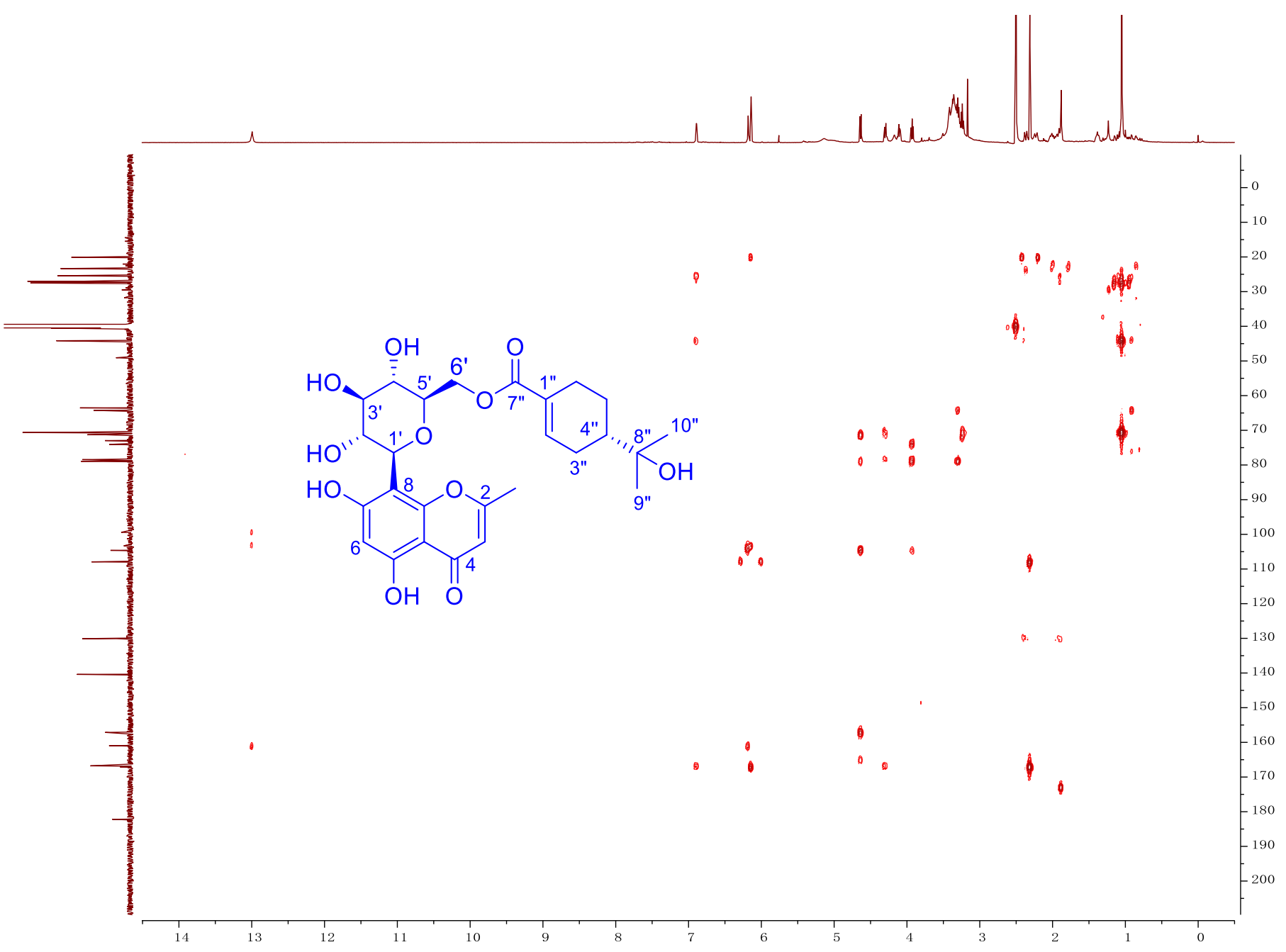

Figure S8. HMBC spectrum of the new compound 1 


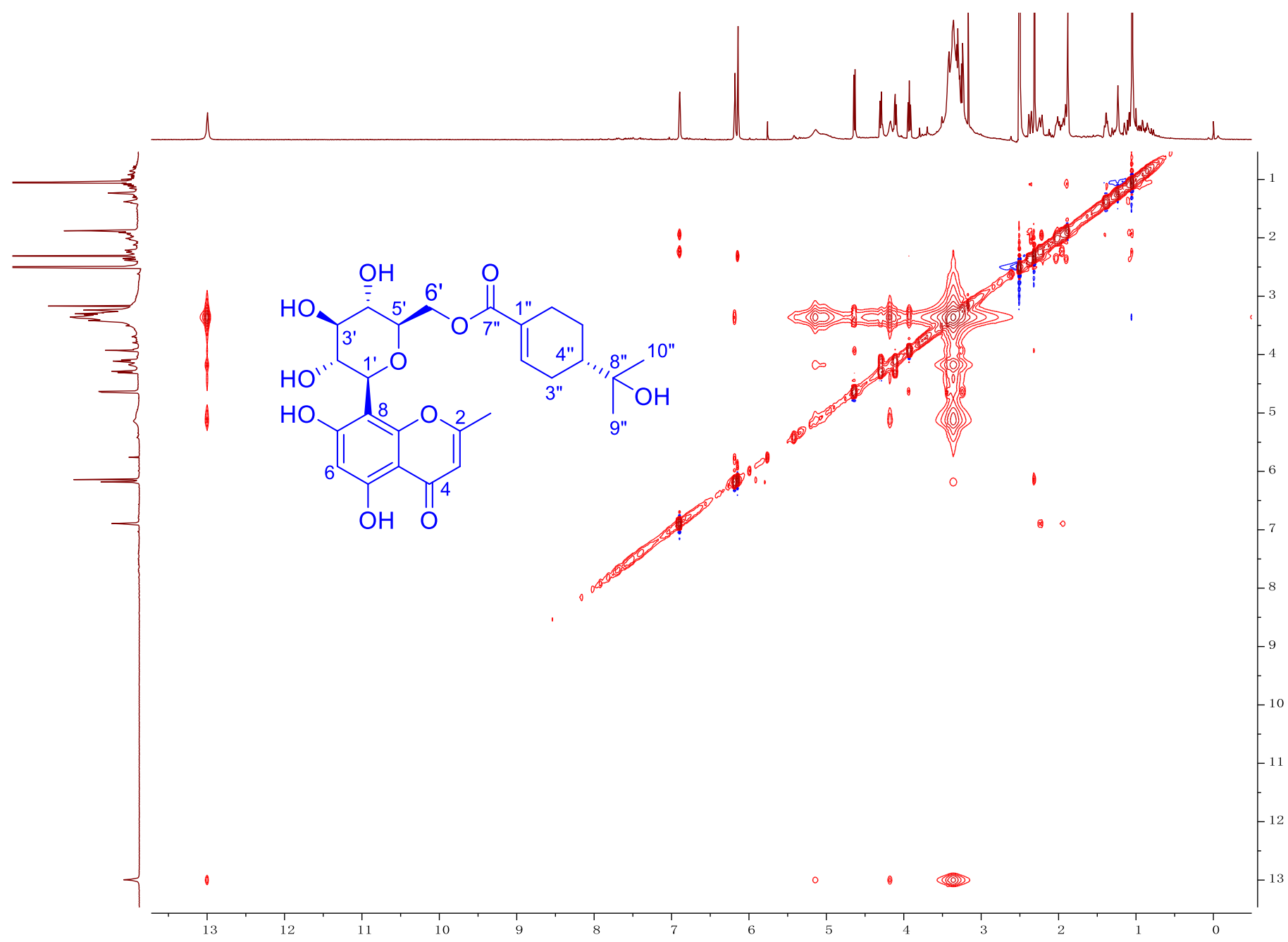

Figure S9. NOESY spectrum of the new compound 1 


\section{Qualitative Analysis Report}

Data Filename

Sample Type

Instrument Name

Acq Method

IRM Calibration Status

Comment
N-MS-98-NEG.d

Sample

Instrument 1

default-20170301-neg.m

Success
Sample Name Sample2

position P1-A2

User Name

Acquired Time $\quad 3 / 20 / 2019$ 3:51:50 PM

DA Method

Sample Group

Info.

User Spectra

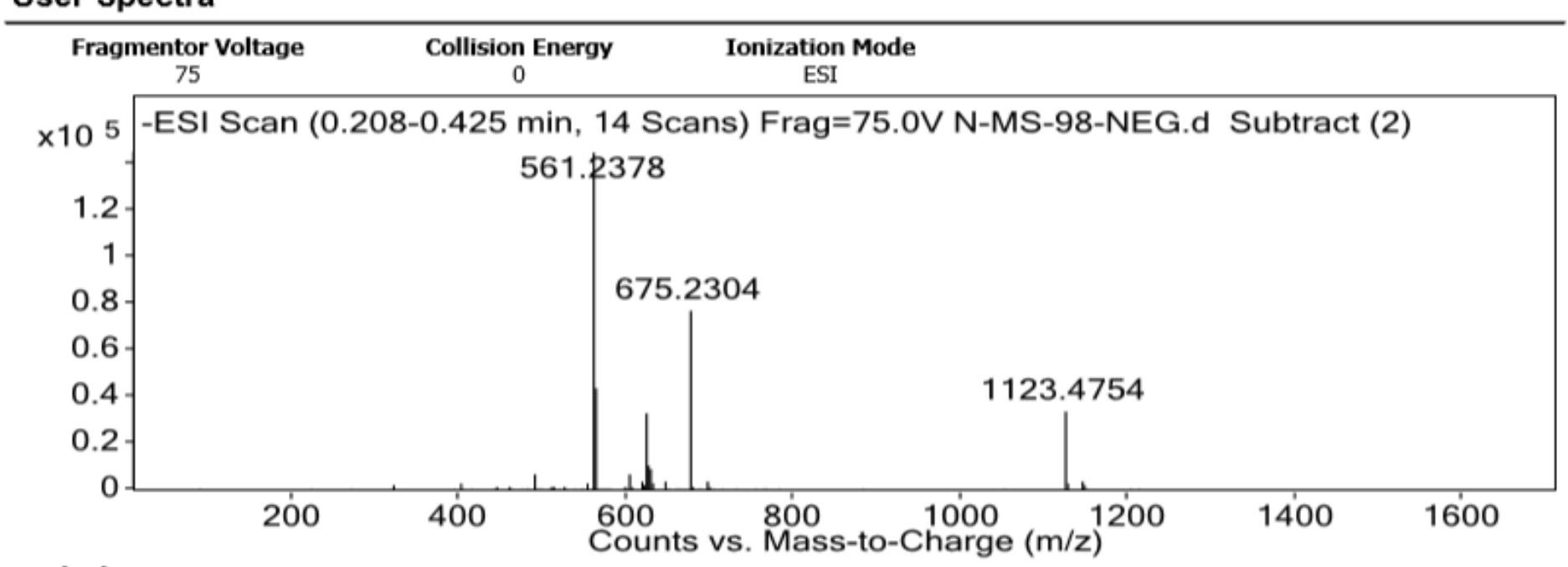

Figure S10. HRESI-MS spectrum of the new compound 2 


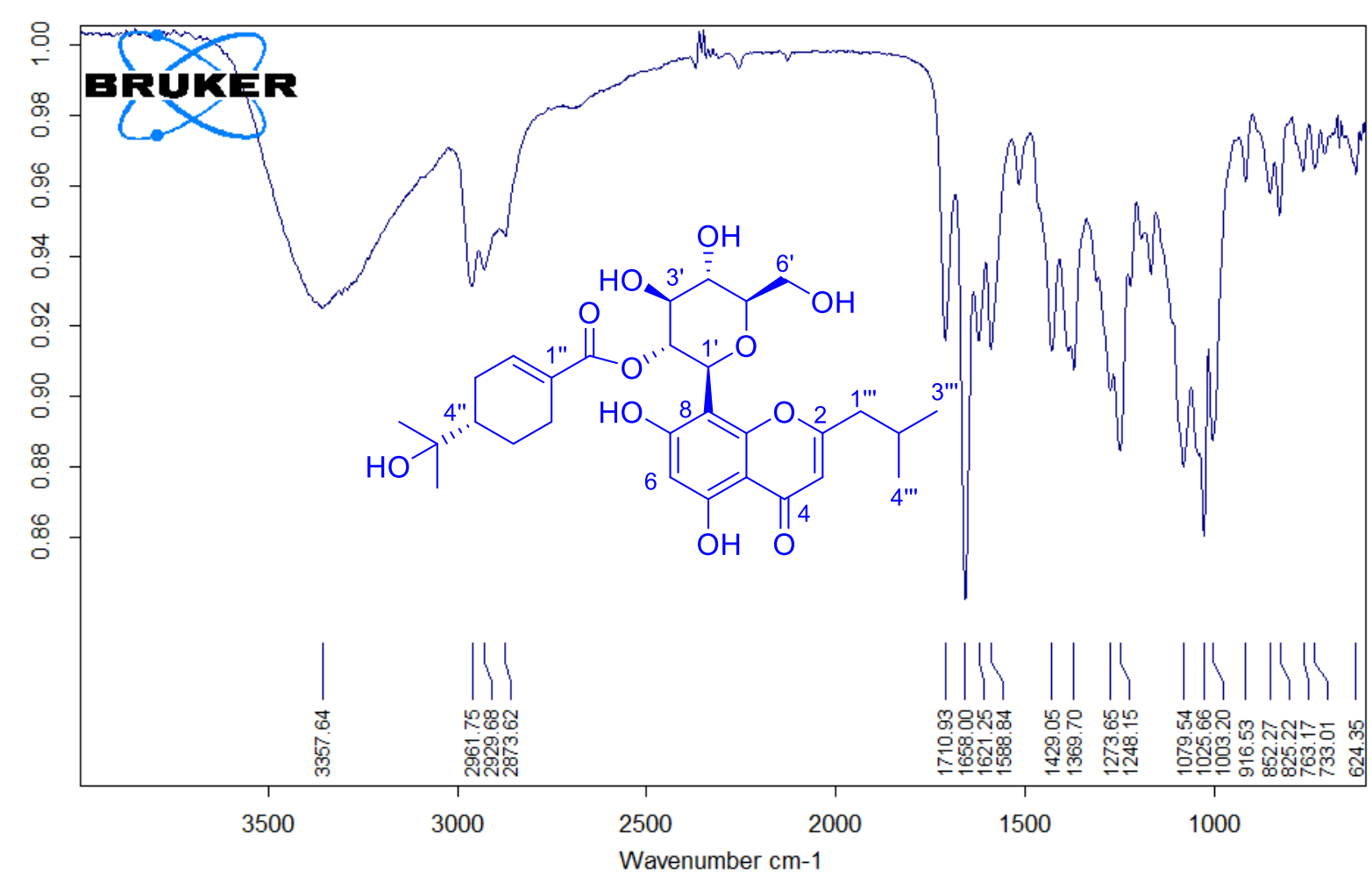

\begin{tabular}{|ll|l|}
\hline D:IUserDatal2014-03-14IFILM.141 & Instrument type and / or accessory & $2019 / 3 / 8$ \\
\hline
\end{tabular}

Page 1/1

Figure S11. IR spectrum of the new compound 2 


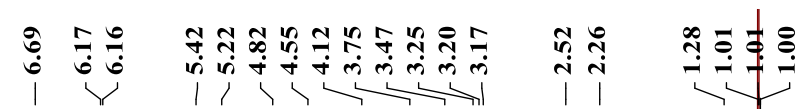
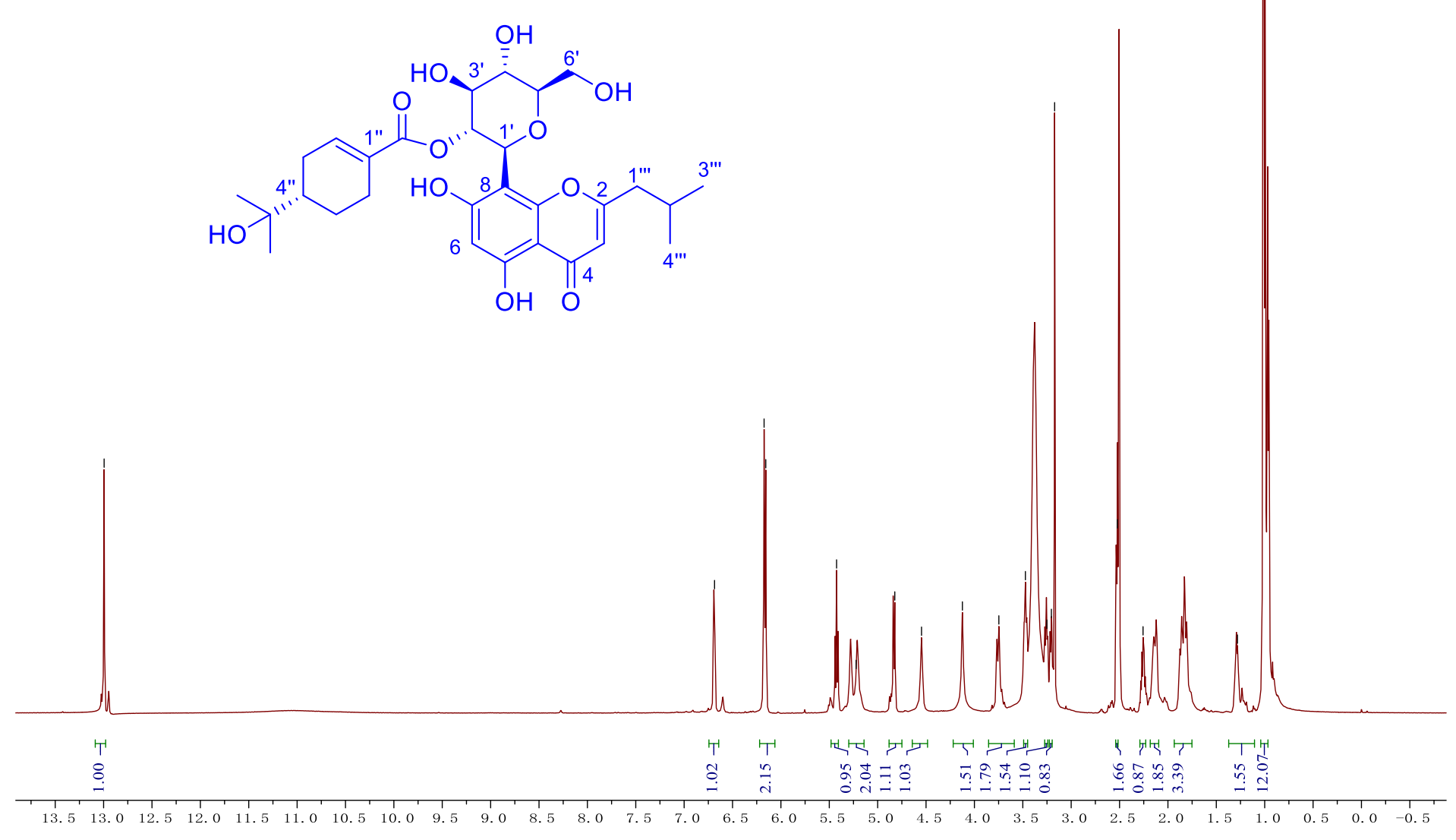

Figure S12. ${ }^{1} \mathrm{H}$ NMR (600 MHz, DMSO- $\left.d_{6}\right)$ spectrum of the new compound 2 

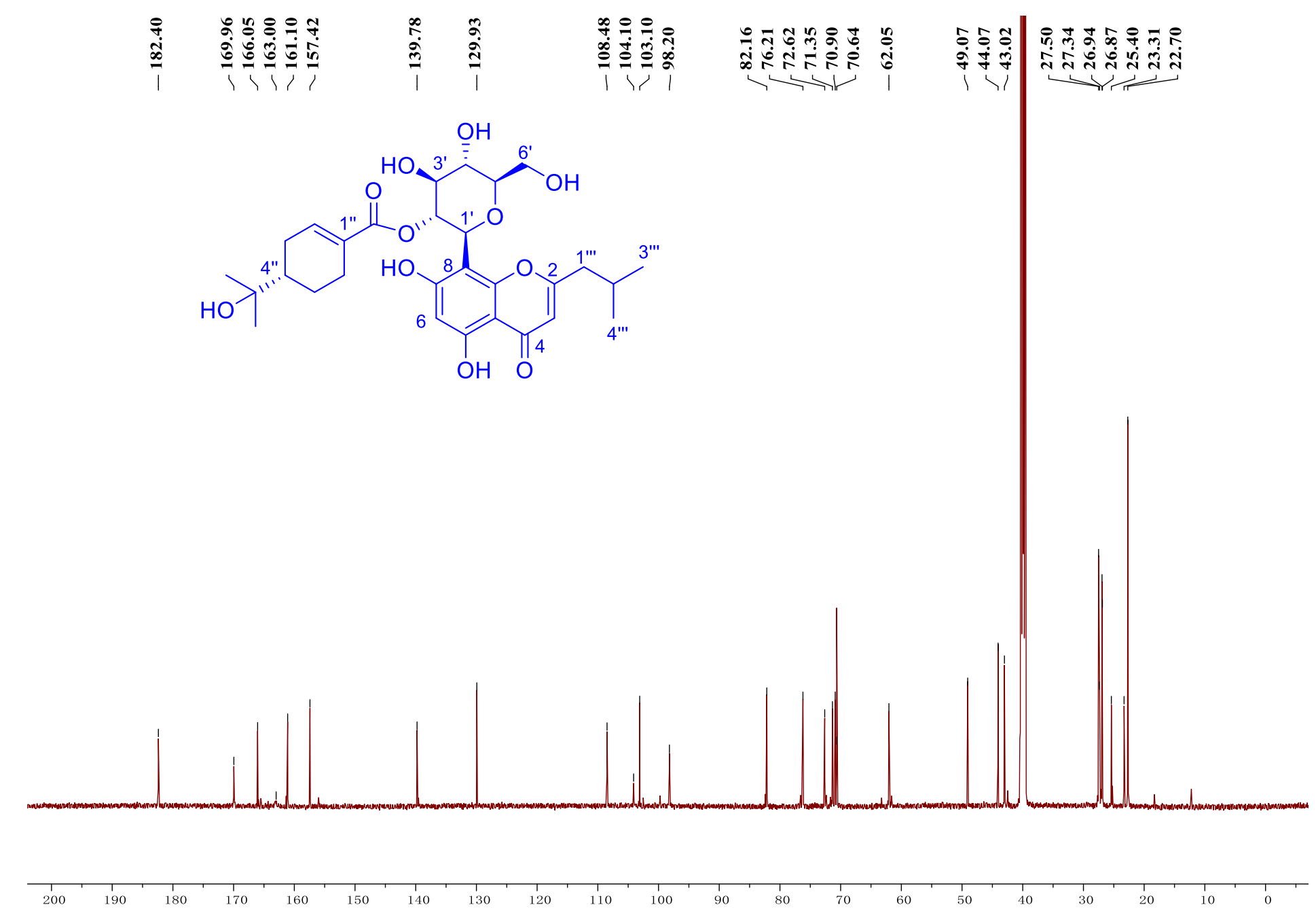

Figure S13. ${ }^{13} \mathrm{C}$ NMR $\left(150 \mathrm{MHz}\right.$, DMSO- $d_{6}$ ) spectrum of the new compound 2 


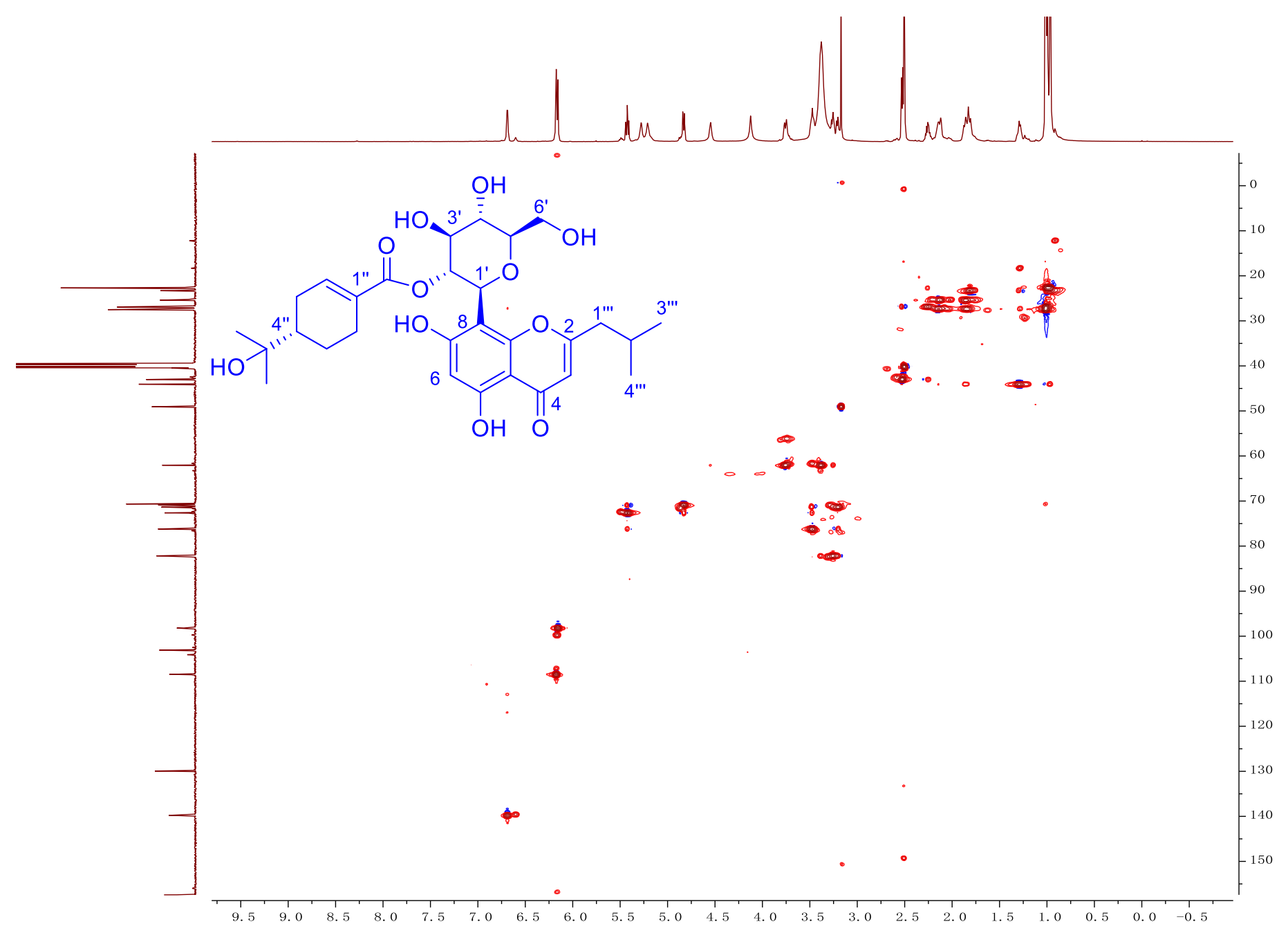

Figure S14. HSQC spectrum of the new compound 2 


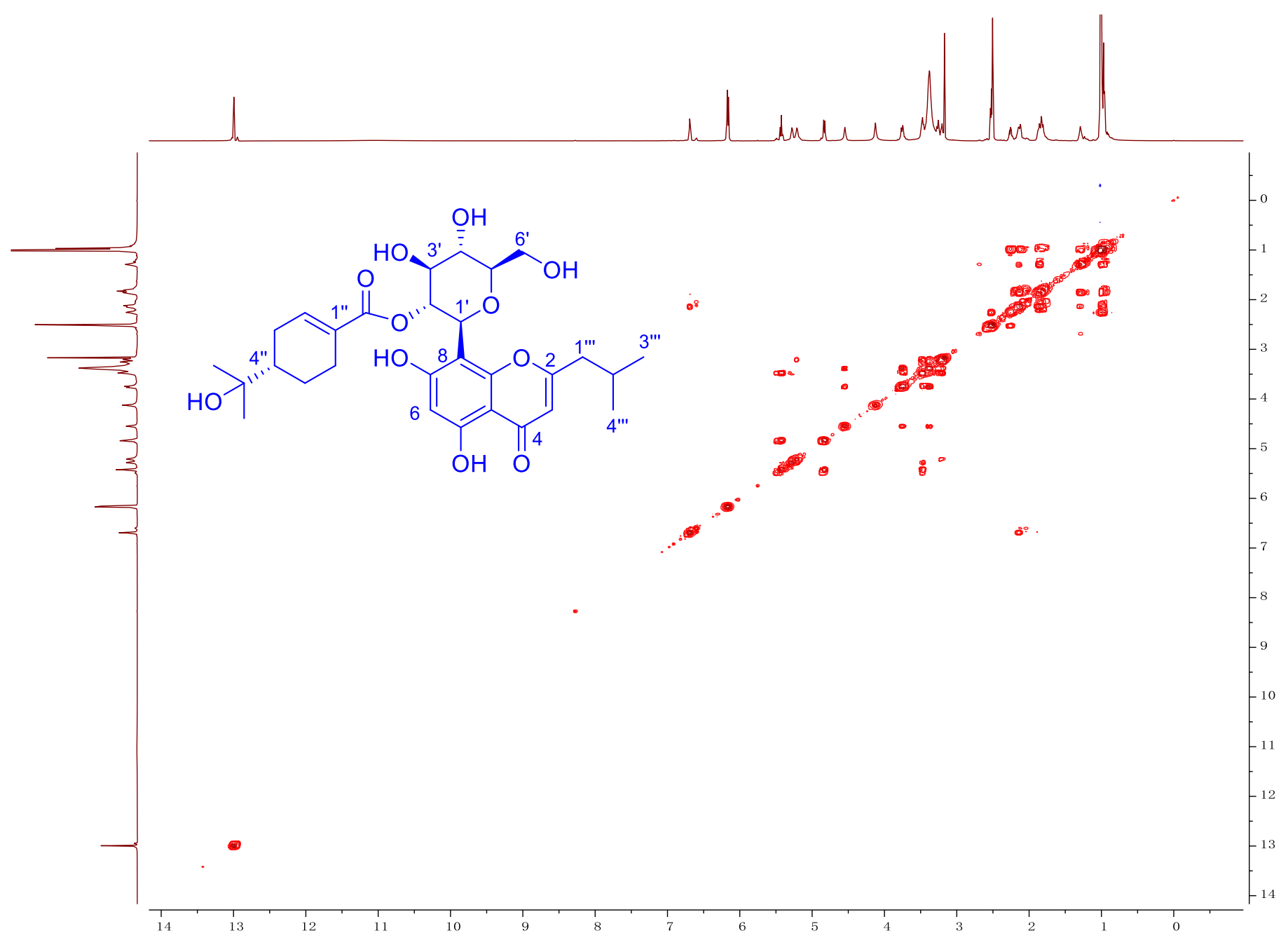

Figure S15. COSY spectrum of the new compound 2 


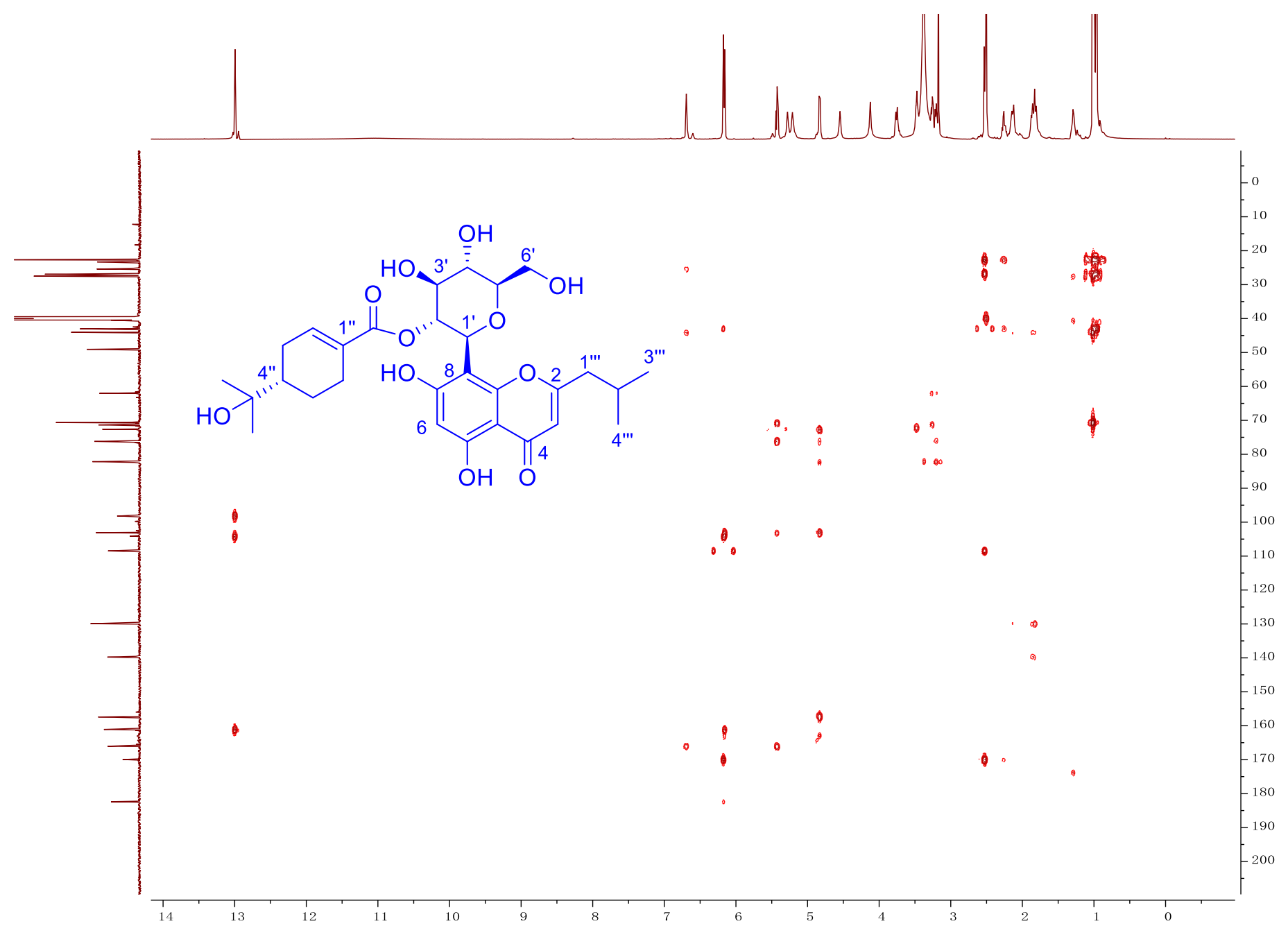

Figure S16. HMBC spectrum of the new compound 2 


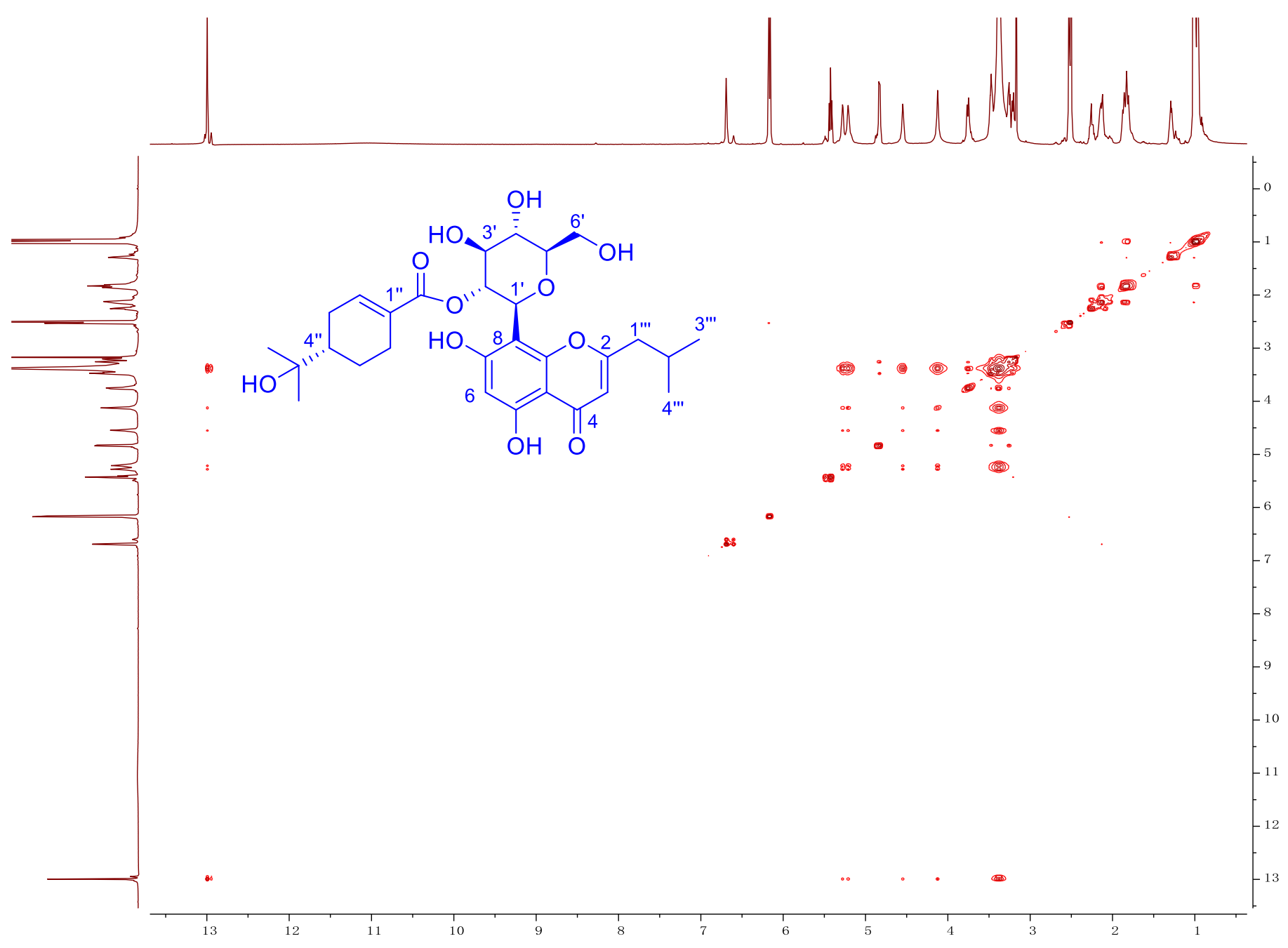

Figure S17. NOESY spectrum of the new compound 2 


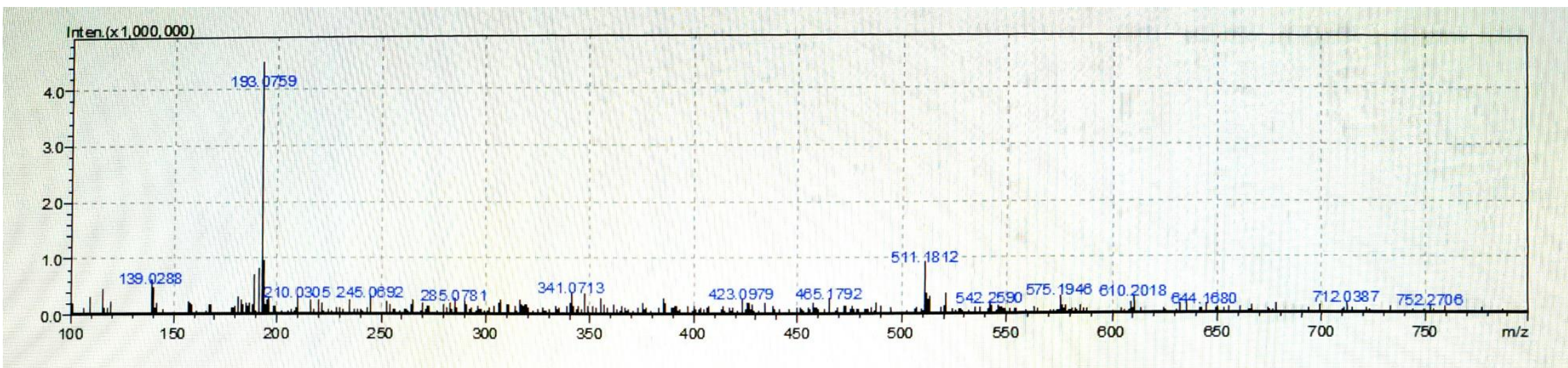

Figure S18. HRESI-MS spectrum of the new compound 5 


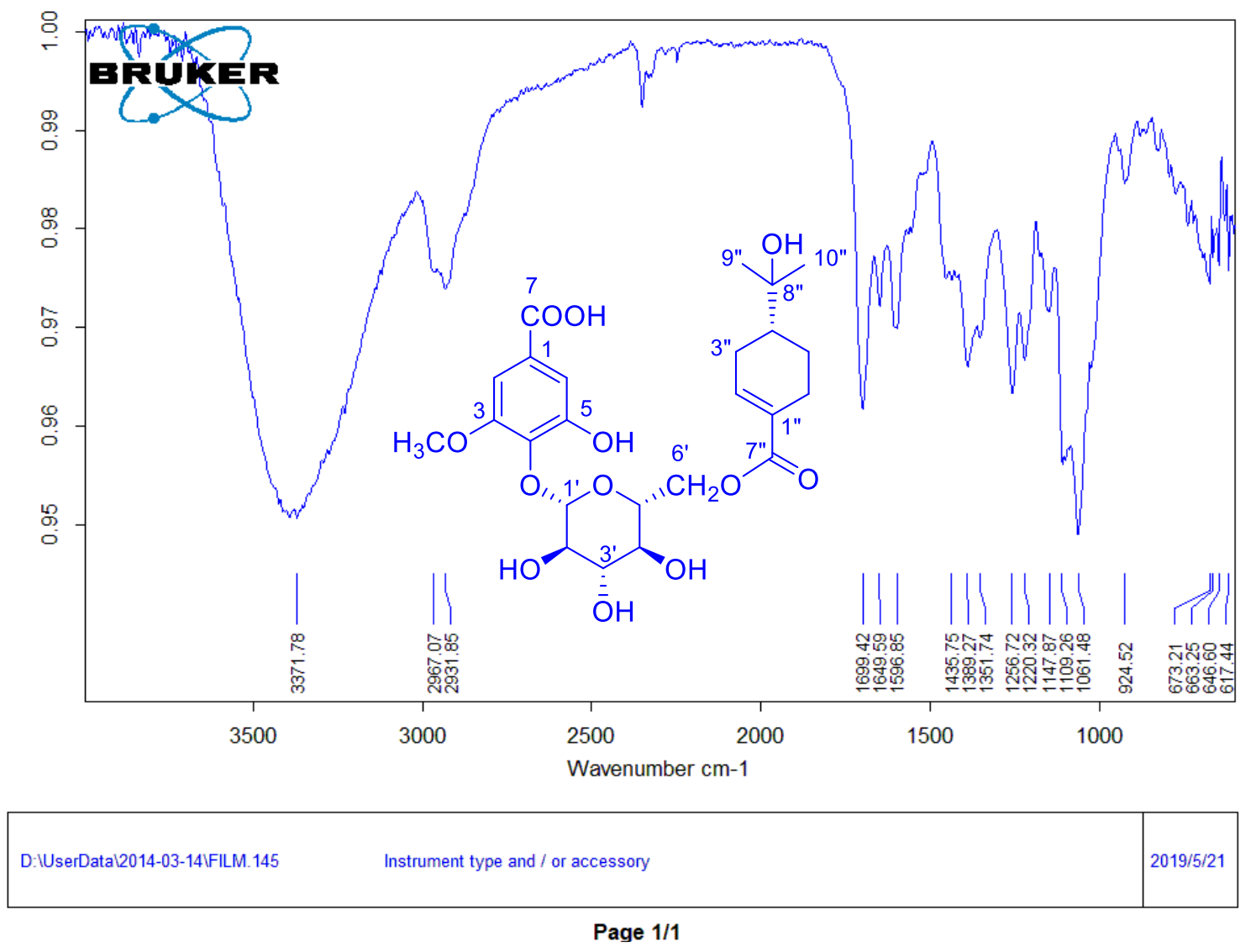

Figure S19. IR spectrum of the new compound $\mathbf{5}$ 


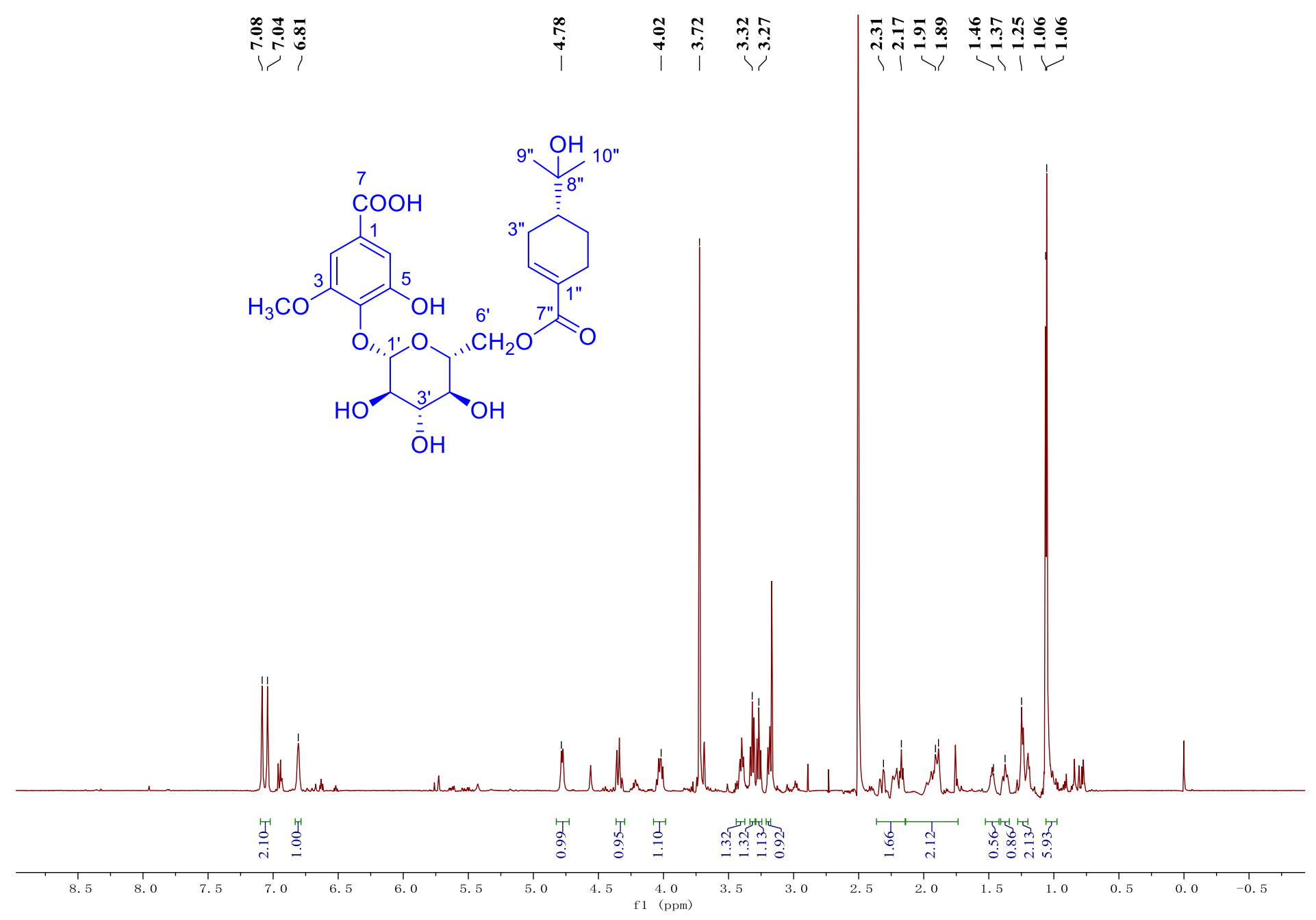

Figure S20. ${ }^{1} \mathrm{H}$ NMR (600 MHz, DMSO- $\left.d_{6}\right)$ spectrum of the new compound 5 


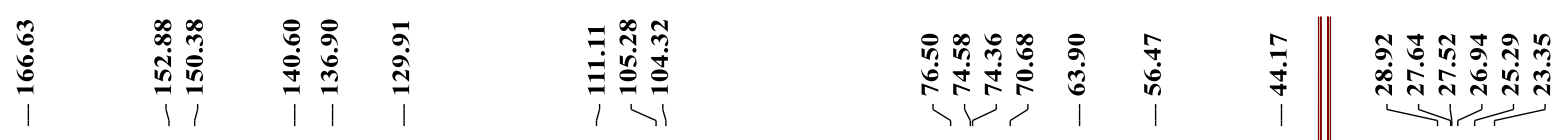
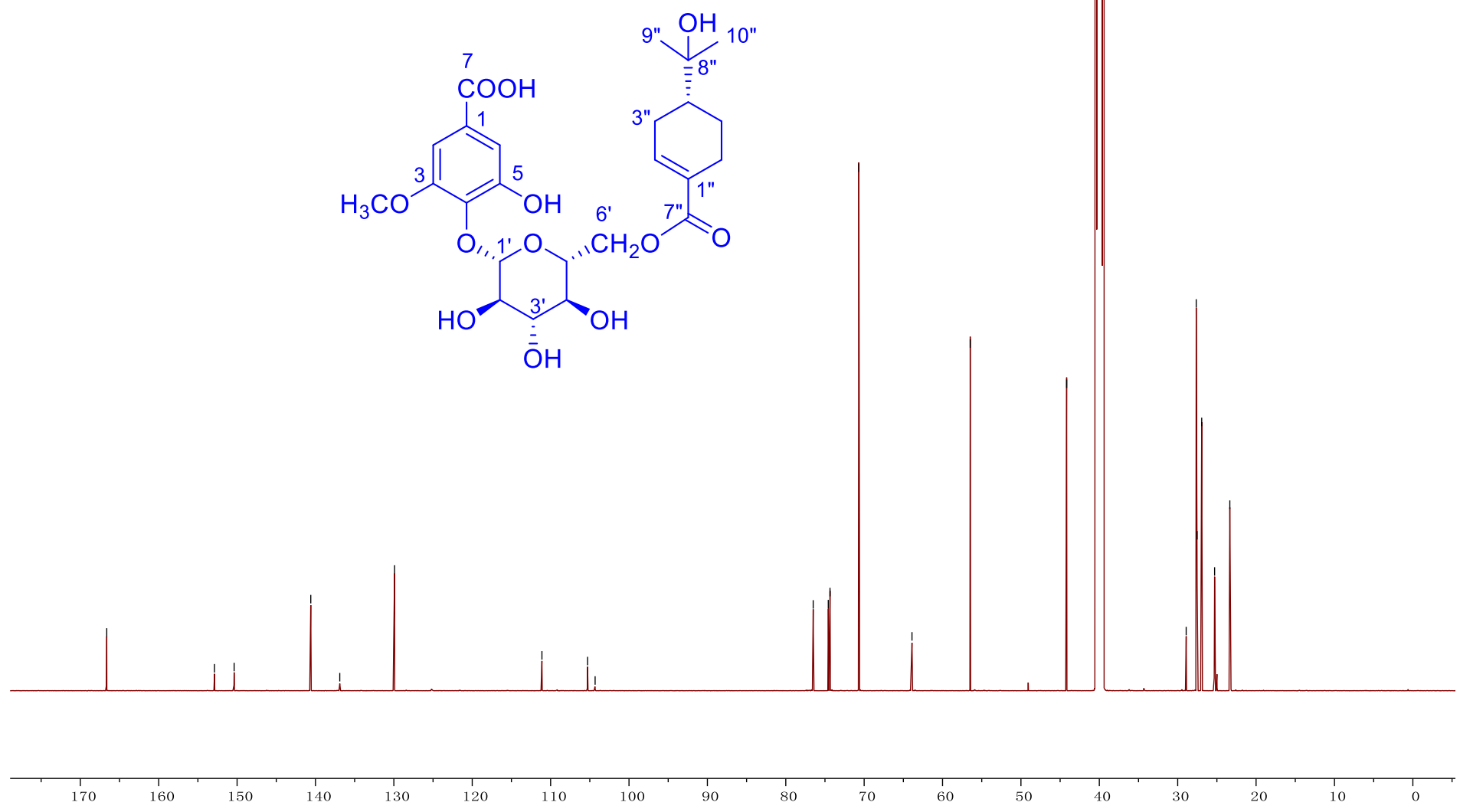

Figure S21. ${ }^{13} \mathrm{C}$ NMR (150 MHz, DMSO- $\left.d_{6}\right)$ spectrum of the new compound 5 

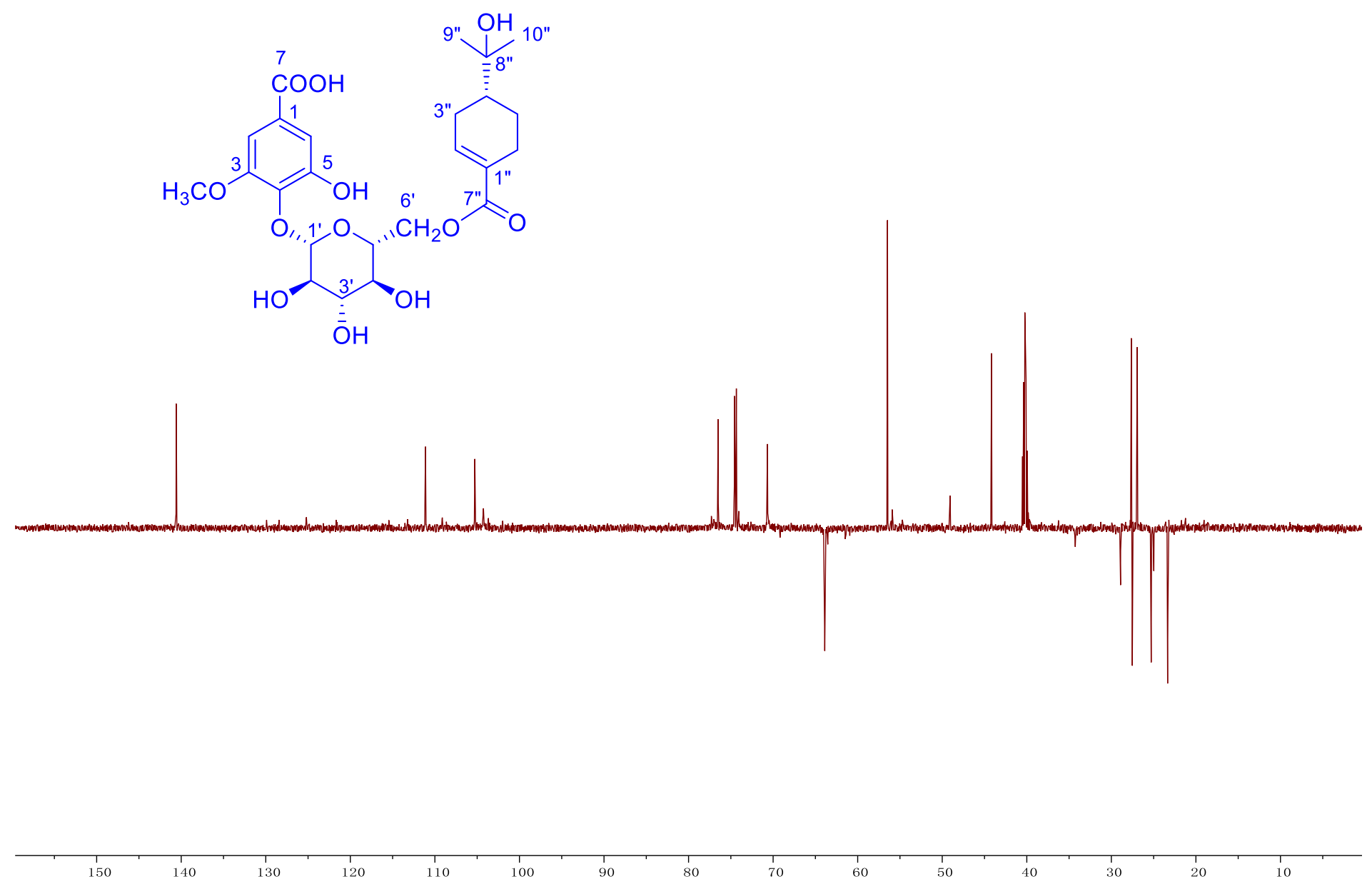

Figure S22. DEPT ( $150 \mathrm{MHz}$, DMSO- $d_{6}$ ) spectrum of the new compound 5 


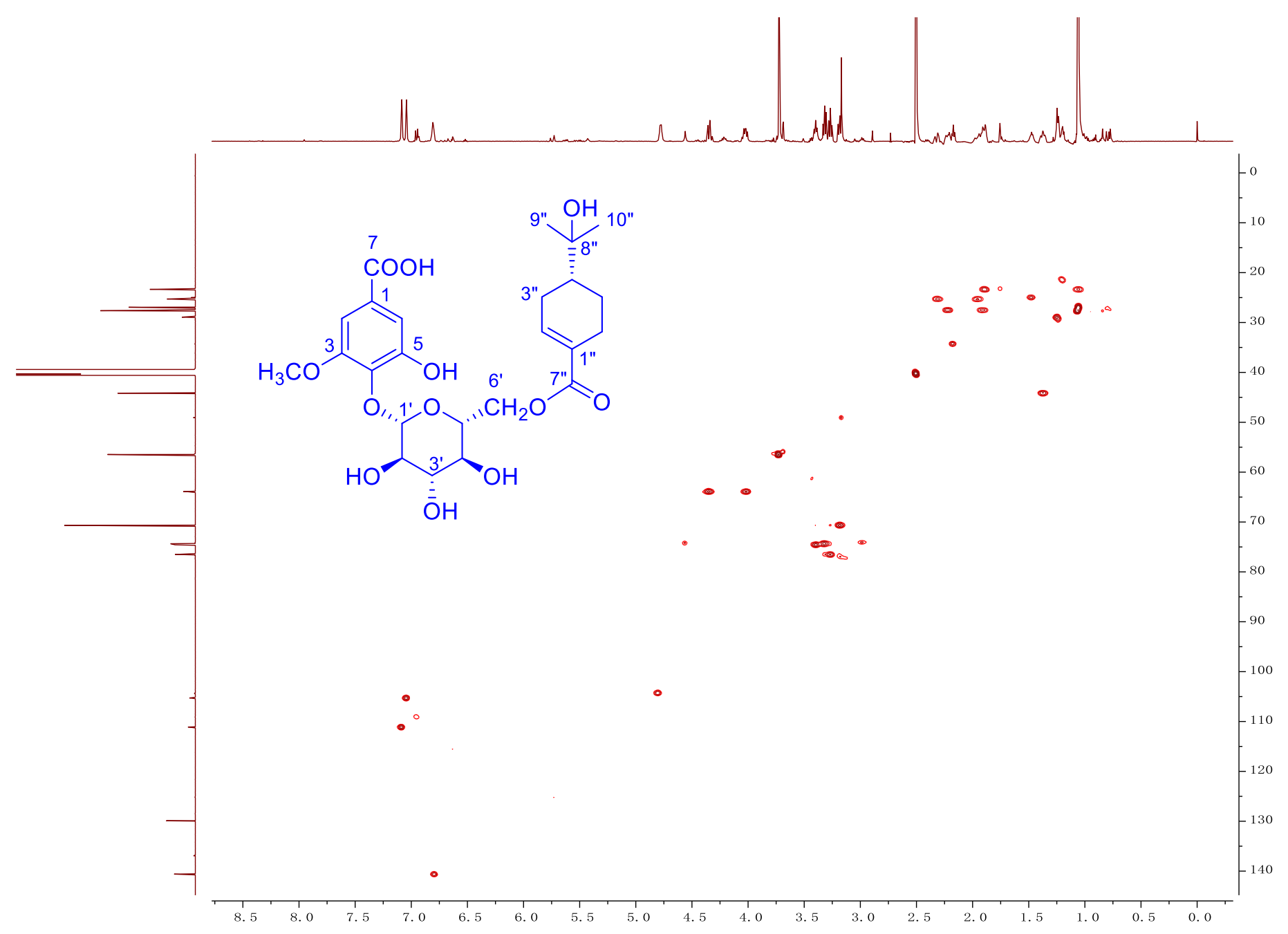

Figure S23. HSQC spectrum of the new compound 5 


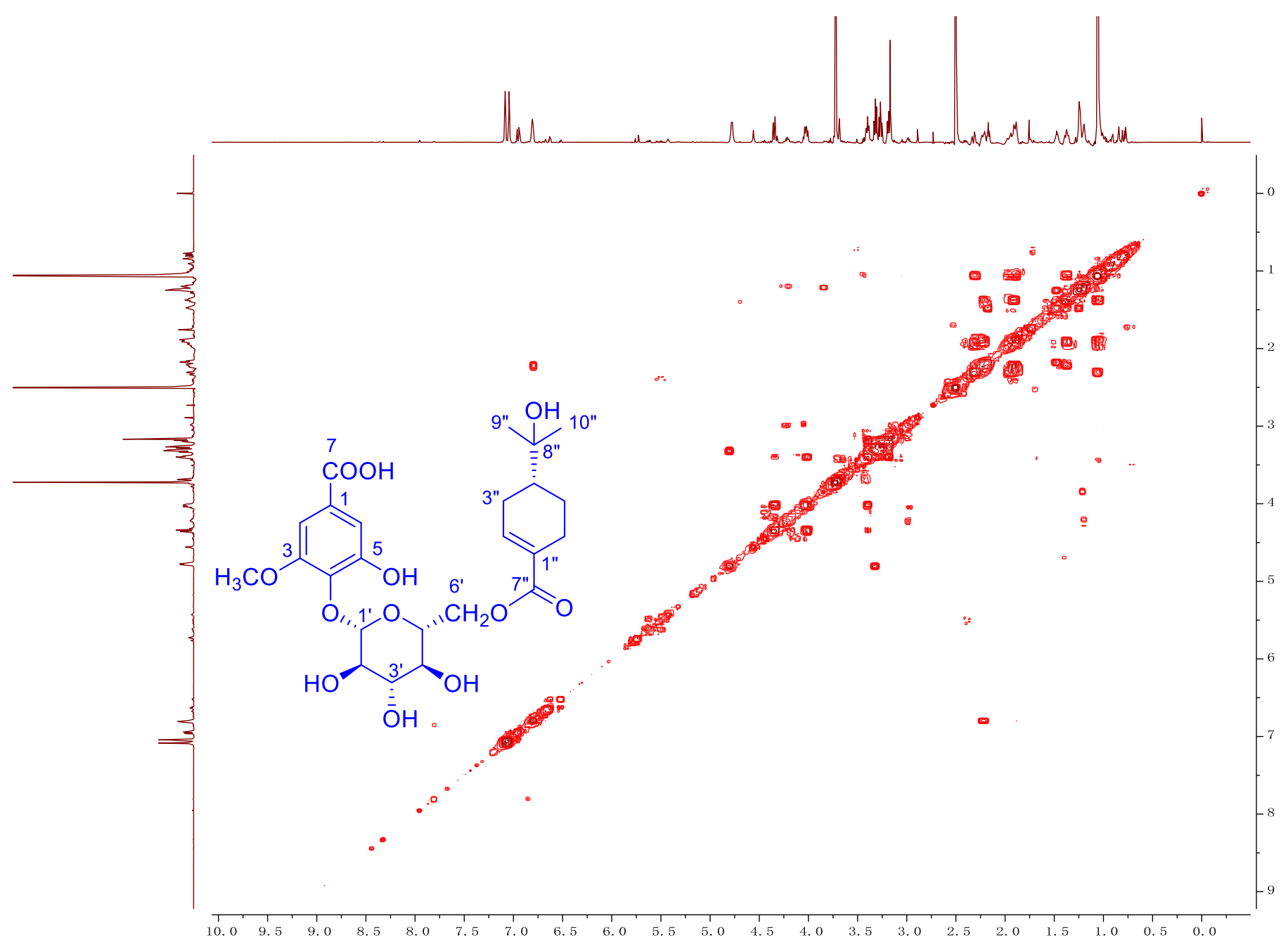

Figure S24. COSY spectrum of the new compound 5 


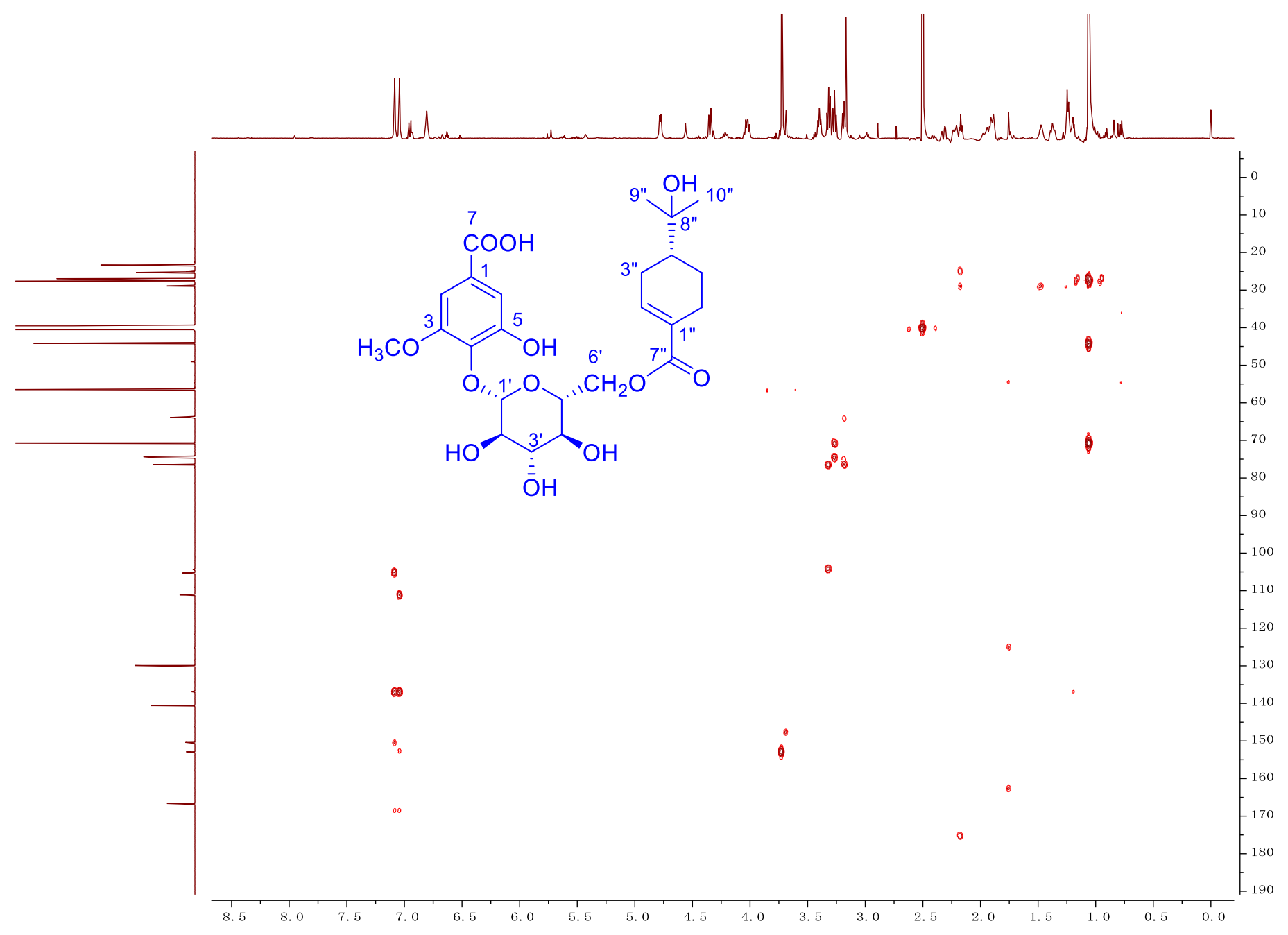

Figure S25. HMBC spectrum of the new compound 5 


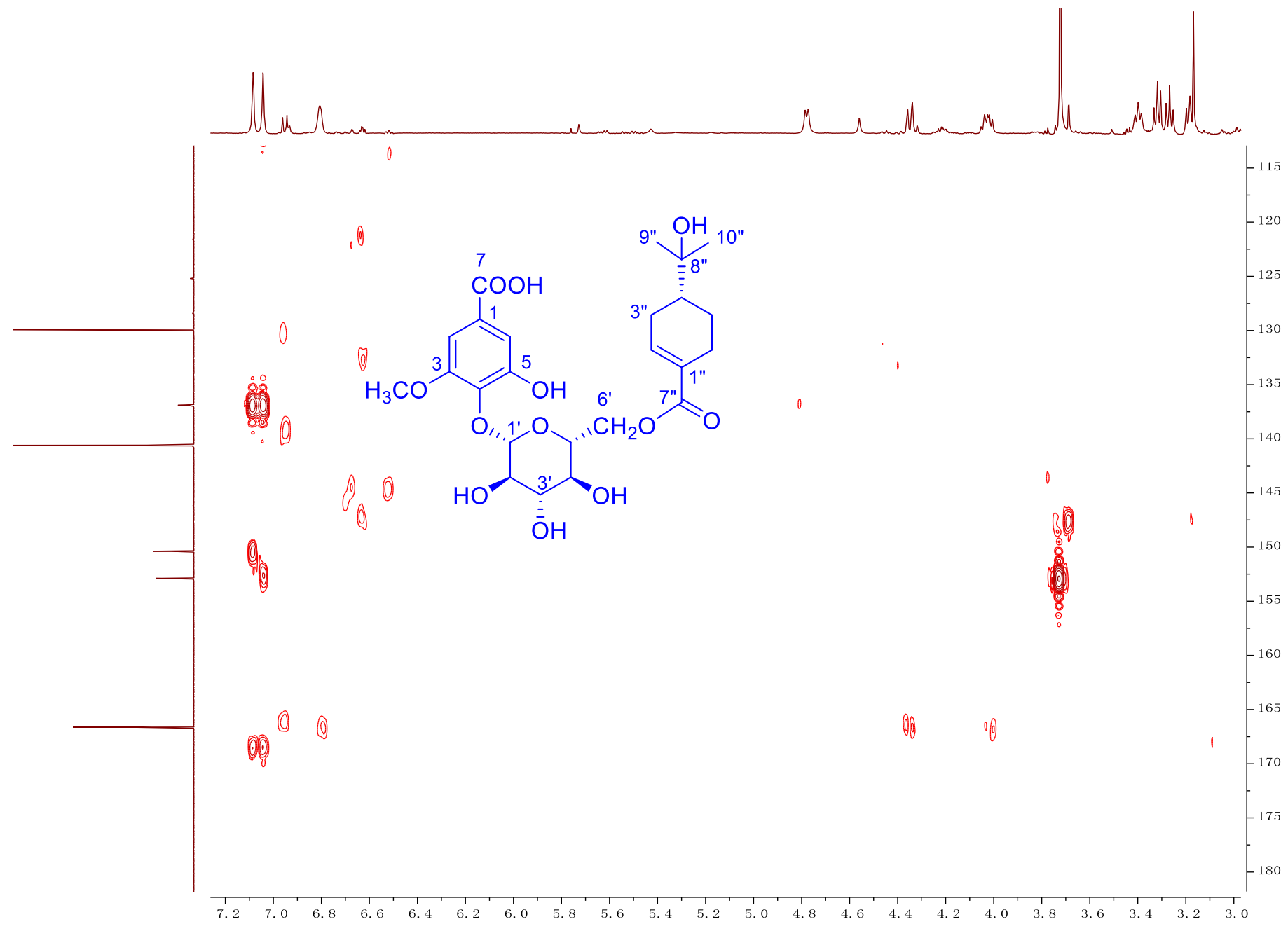

Figure S26. Expand HMBC spectrum of the new compound 5 


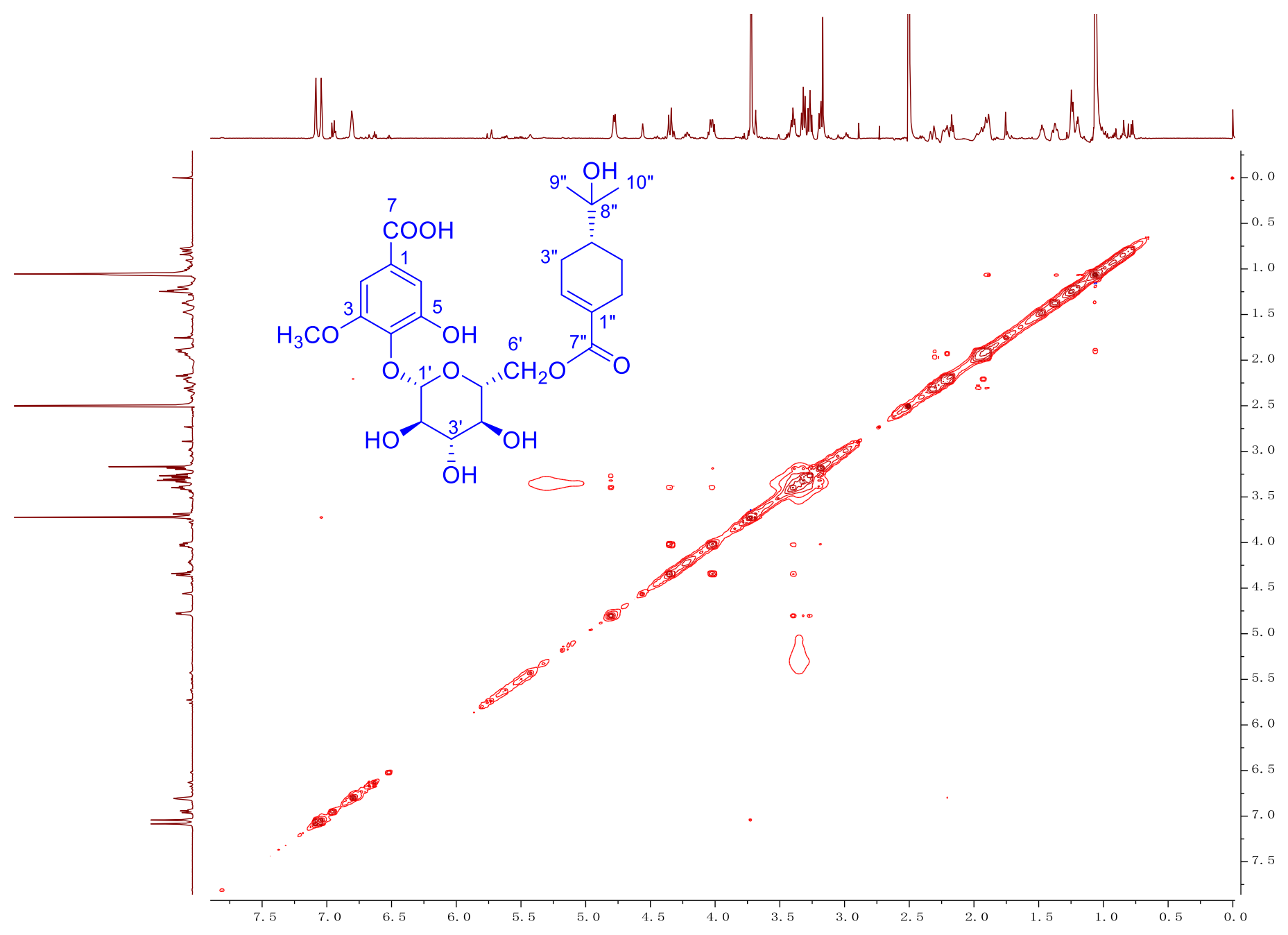

Figure S27. NOESY spectrum of the new compound 5 


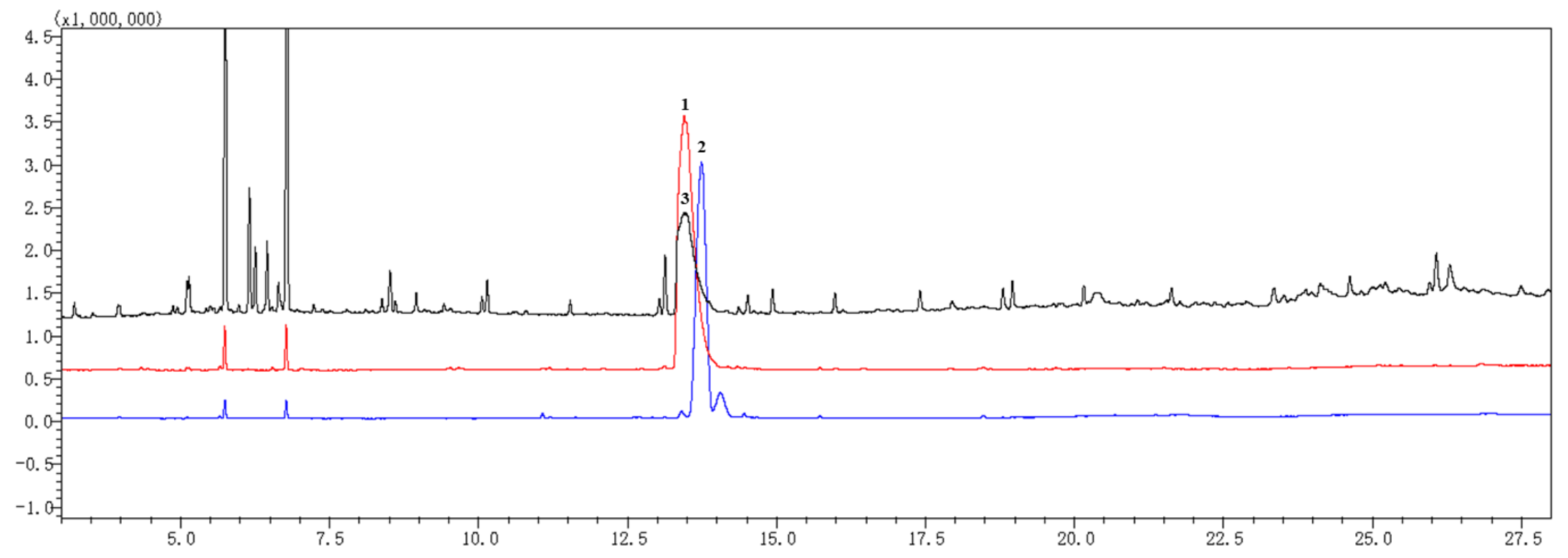

Figure S28. GC analysis of derivatives of standard D-glucose, L-glucose and sugar residue derivative of compound $\mathbf{5}$

Peak 1: derivative of standard D-glucose retention time $=13.45 \mathrm{~min}$; Peak 2: derivative of standard L-glucose retention time $=13.74$ min; Peak 3: sugar residue derivative of compound 5 retention time $=13.48 \mathrm{~min}$; Red line: derivative of standard D-glucose; Blue line: derivative of standard L-glucose; Black line: sugar residue derivative of compound $\mathbf{5}$. 


\section{Qualitative Analysis Report}

$\begin{array}{llll}\text { Data Filename } & \text { N-MS-96-NEG.d } & \text { Sample Name } & \text { Sample3 } \\ \text { Sample Type } & \text { Sample } & \text { Position } & \text { P1-A3 } \\ \text { Instrument Name } & \text { Instrument 1 } & \text { User Name } & \\ \text { Acq Method } & \text { default-20170301-neg.m } & \text { Acquired Time } & \text { 3/20/2019 3:53:42 PM } \\ \text { IRM Calibration Status } & \text { Success } & \text { DA Method } & \text { default_Analysis.m }\end{array}$

Comment

Sample Group Info.

\section{User Spectra}

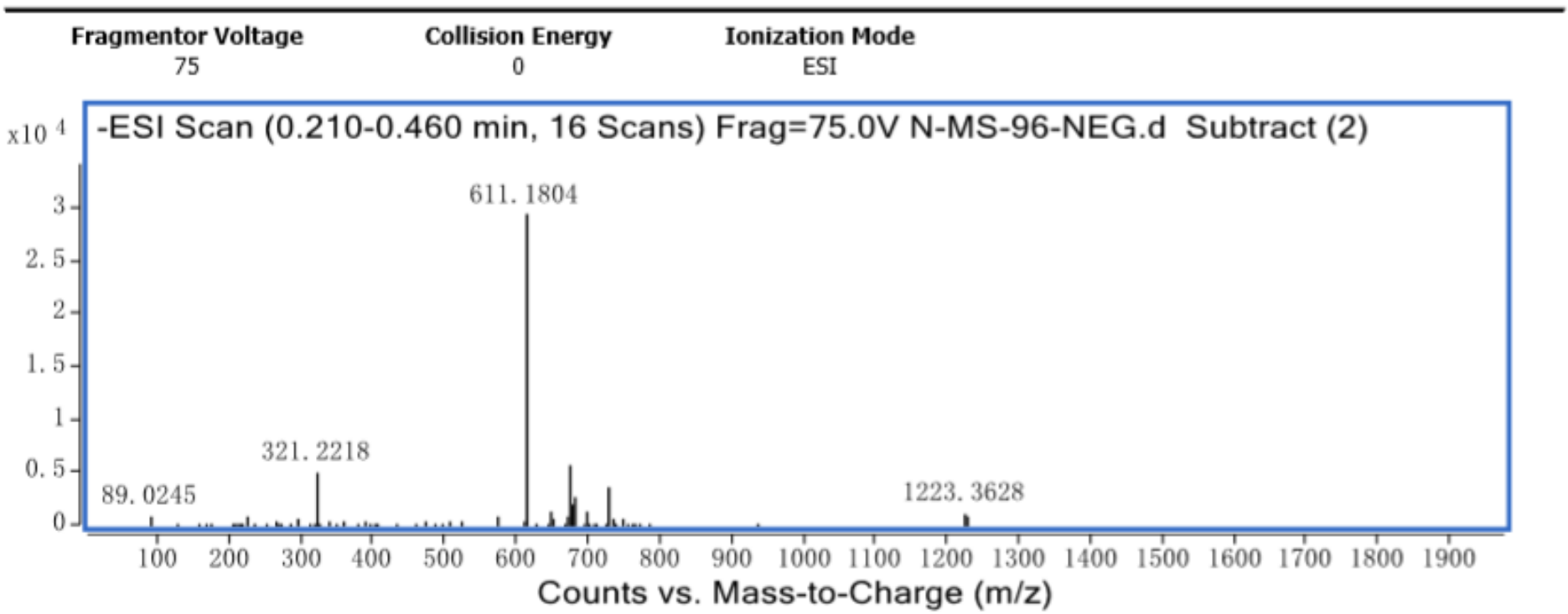

Figure S29. HRESI-MS spectrum of the new compound 6 


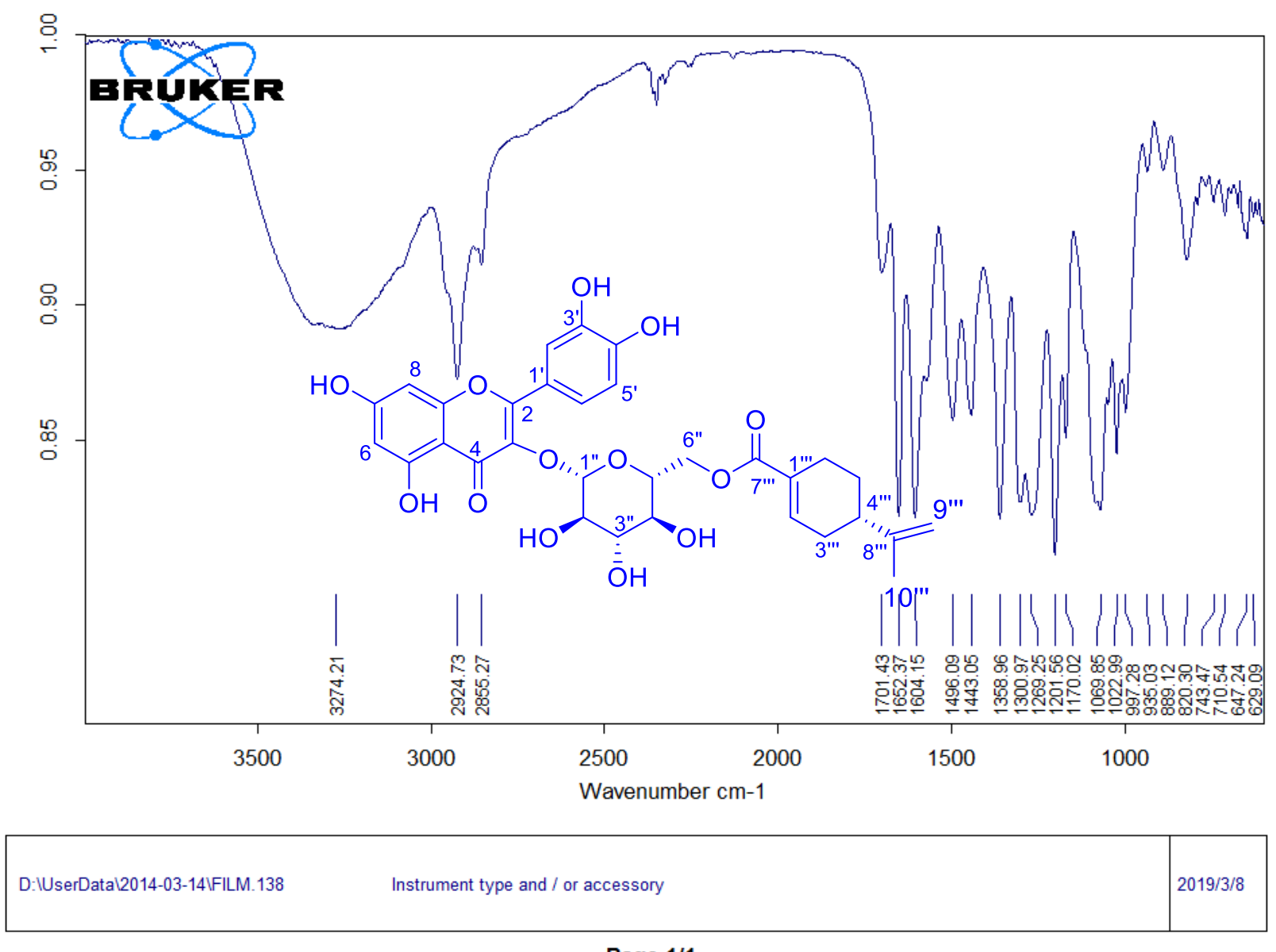

Page 1/1

Figure S30. IR spectrum of the new compound $\mathbf{6}$ 


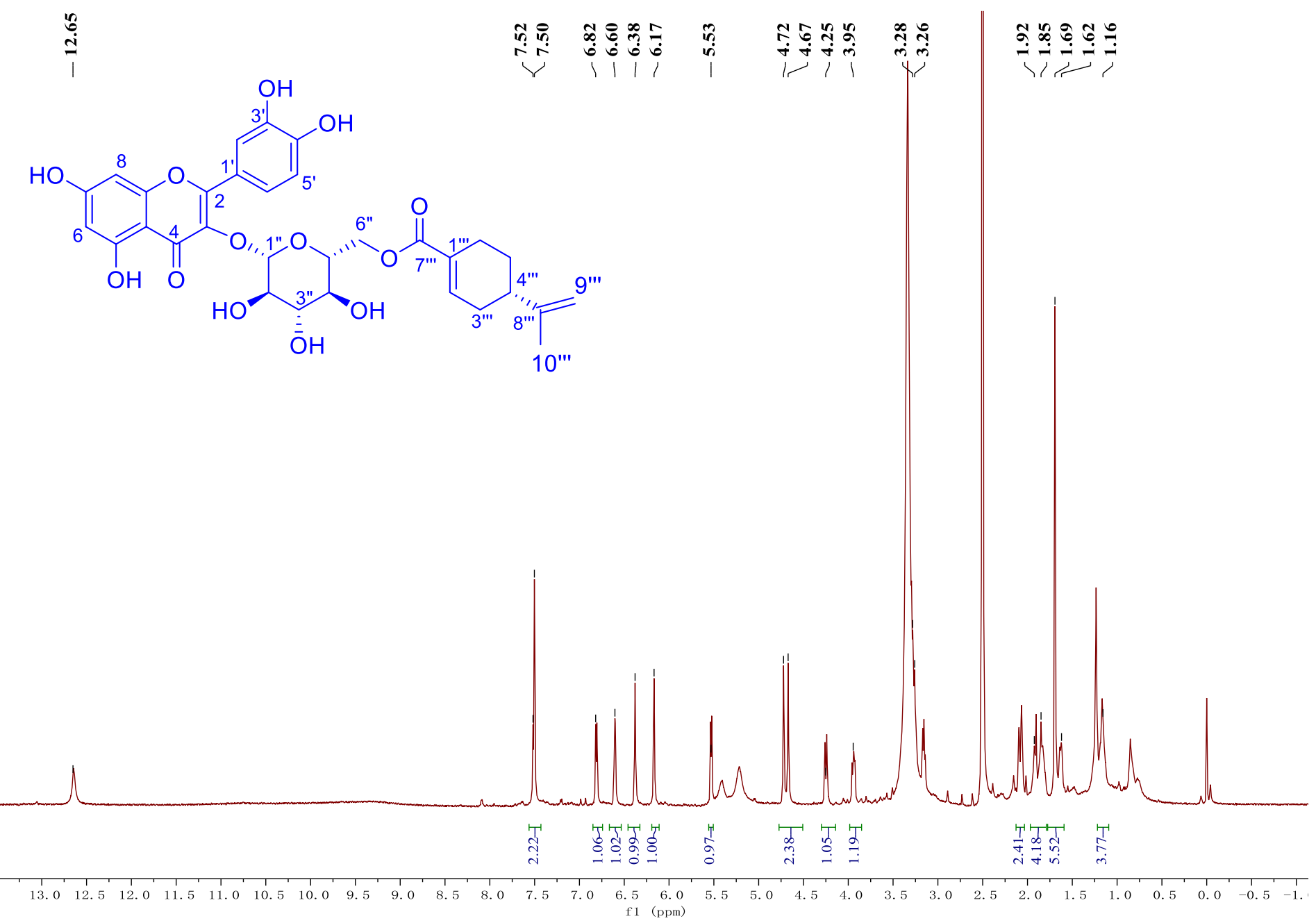

Figure S31. ${ }^{1} \mathrm{H}$ NMR $\left(600 \mathrm{MHz}\right.$, DMSO- $\left.d_{6}\right)$ spectrum of the new compound 6 


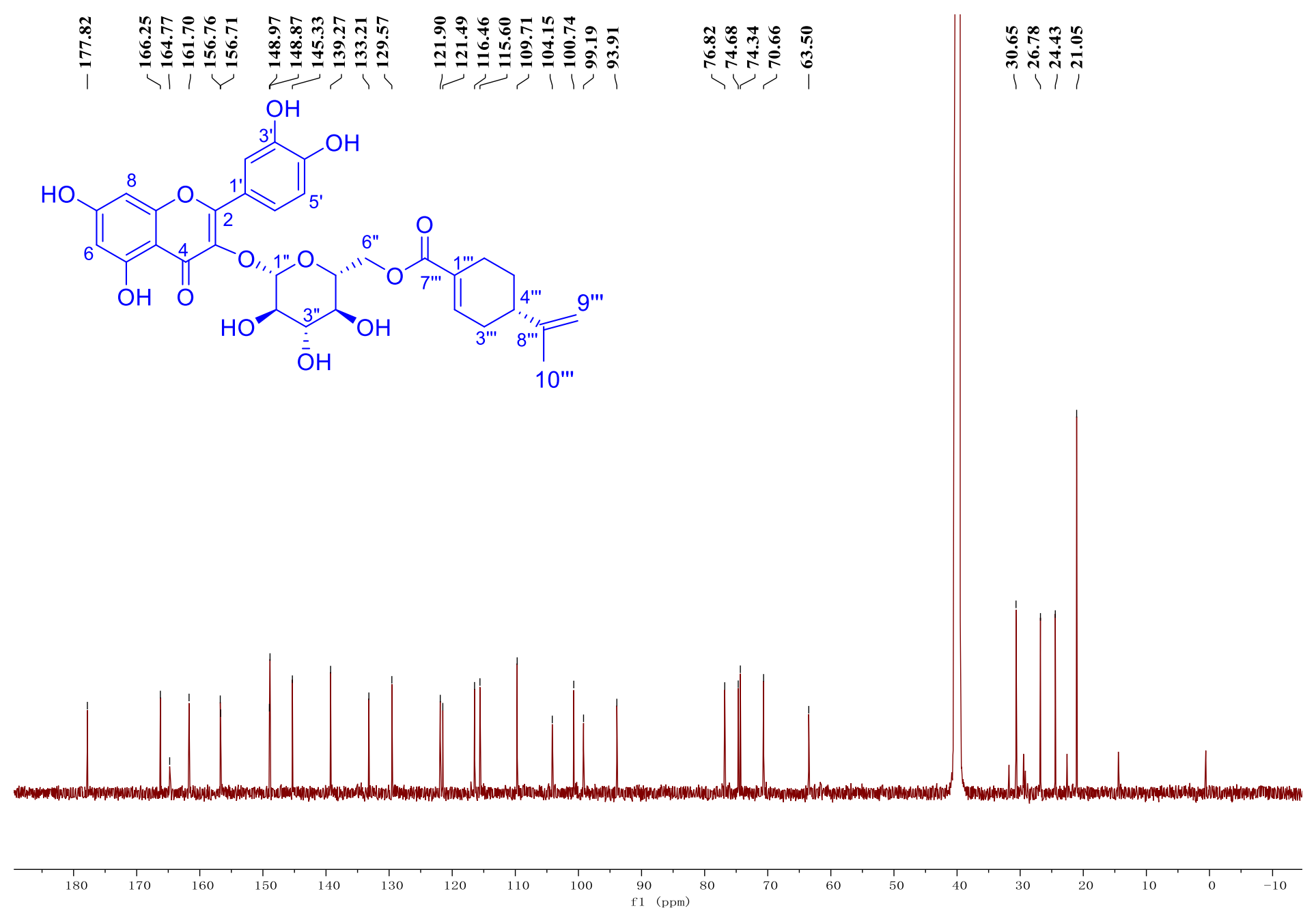

Figure S32. ${ }^{13} \mathrm{C}$ NMR (150 MHz, DMSO- $\left.d_{6}\right)$ spectrum of the new compound 6 

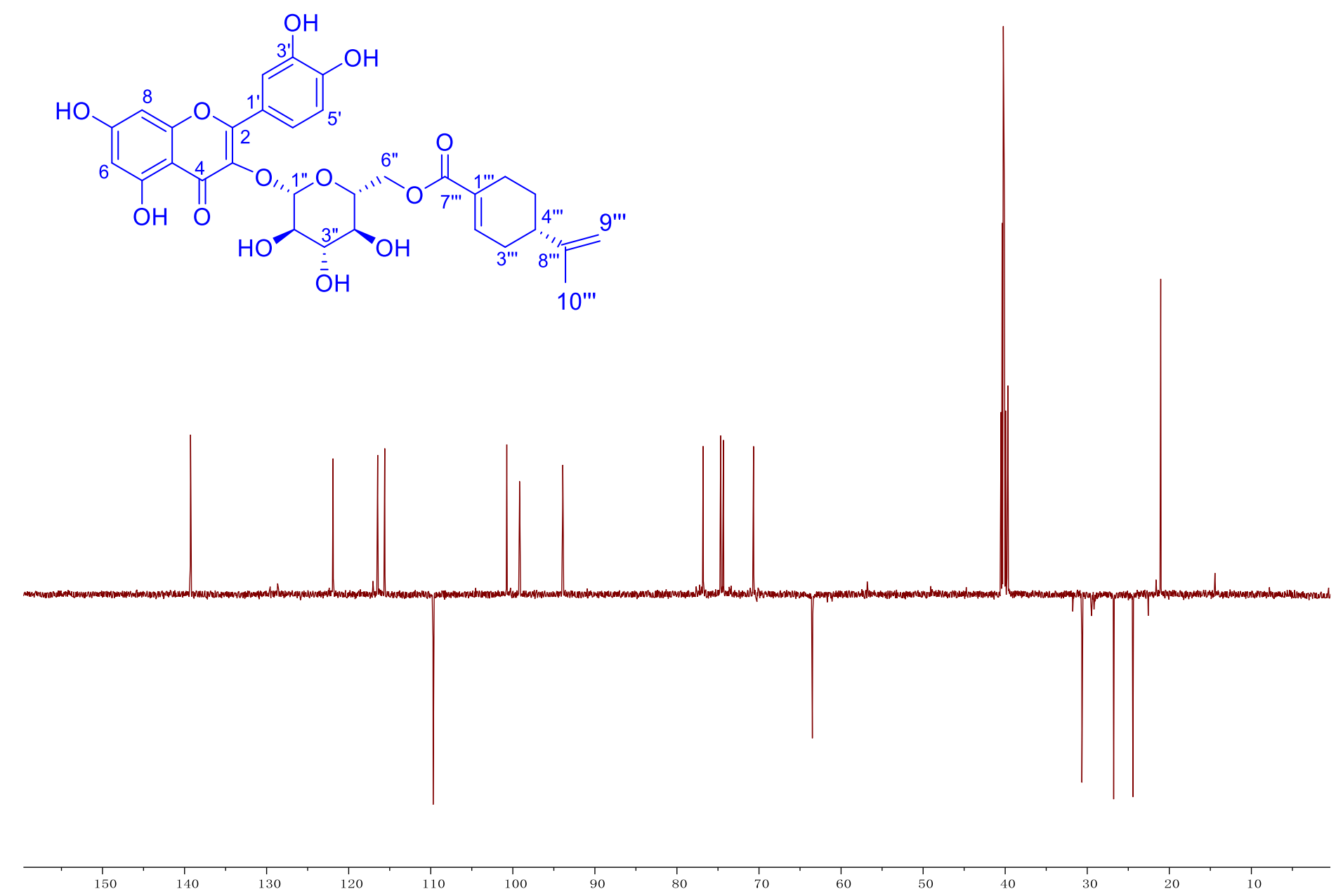

Figure S33. DEPT (150 MHz, DMSO- $d_{6}$ ) spectrum of the new compound 6 


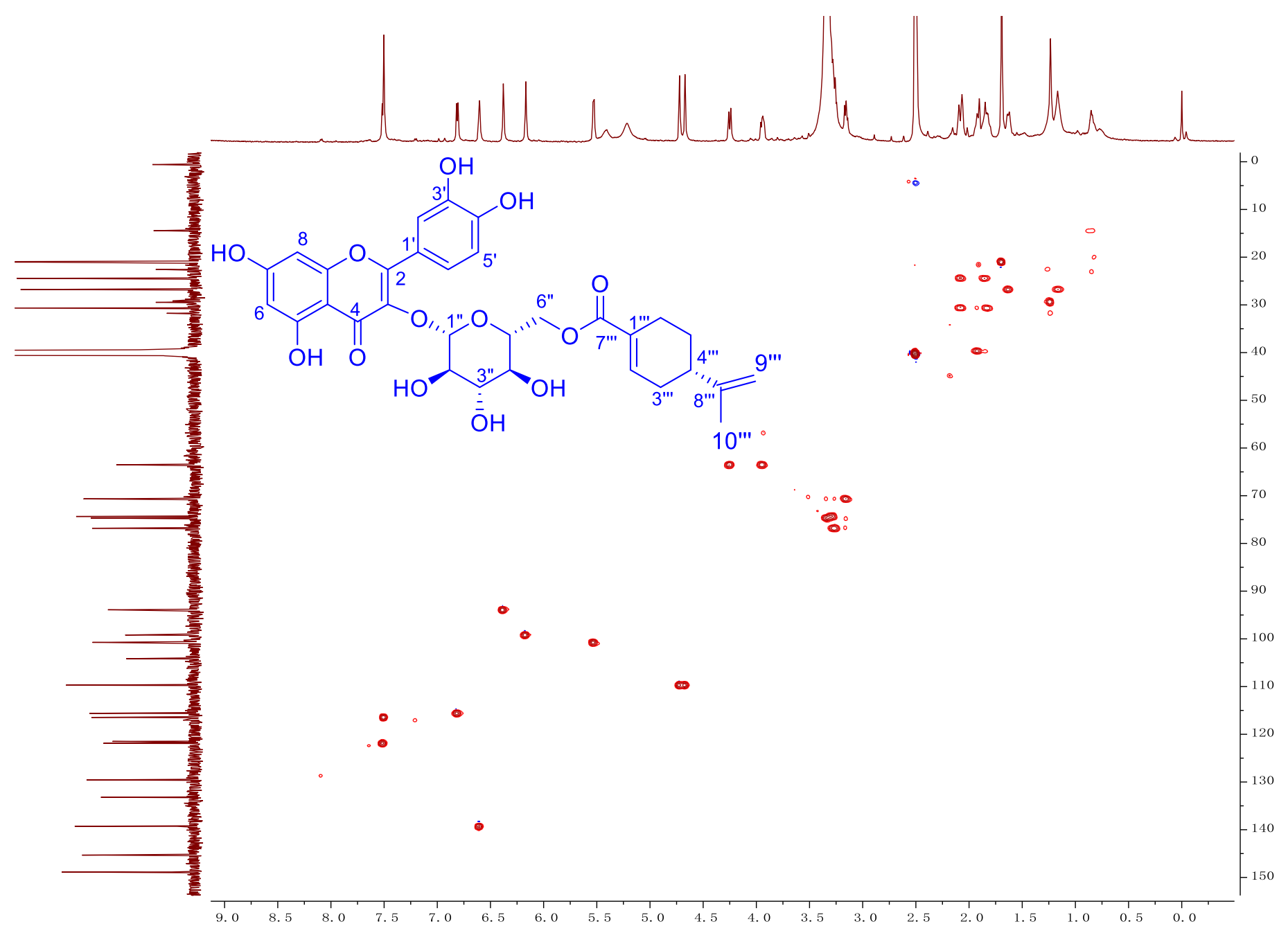

Figure S34. HSQC spectrum of the new compound 6 


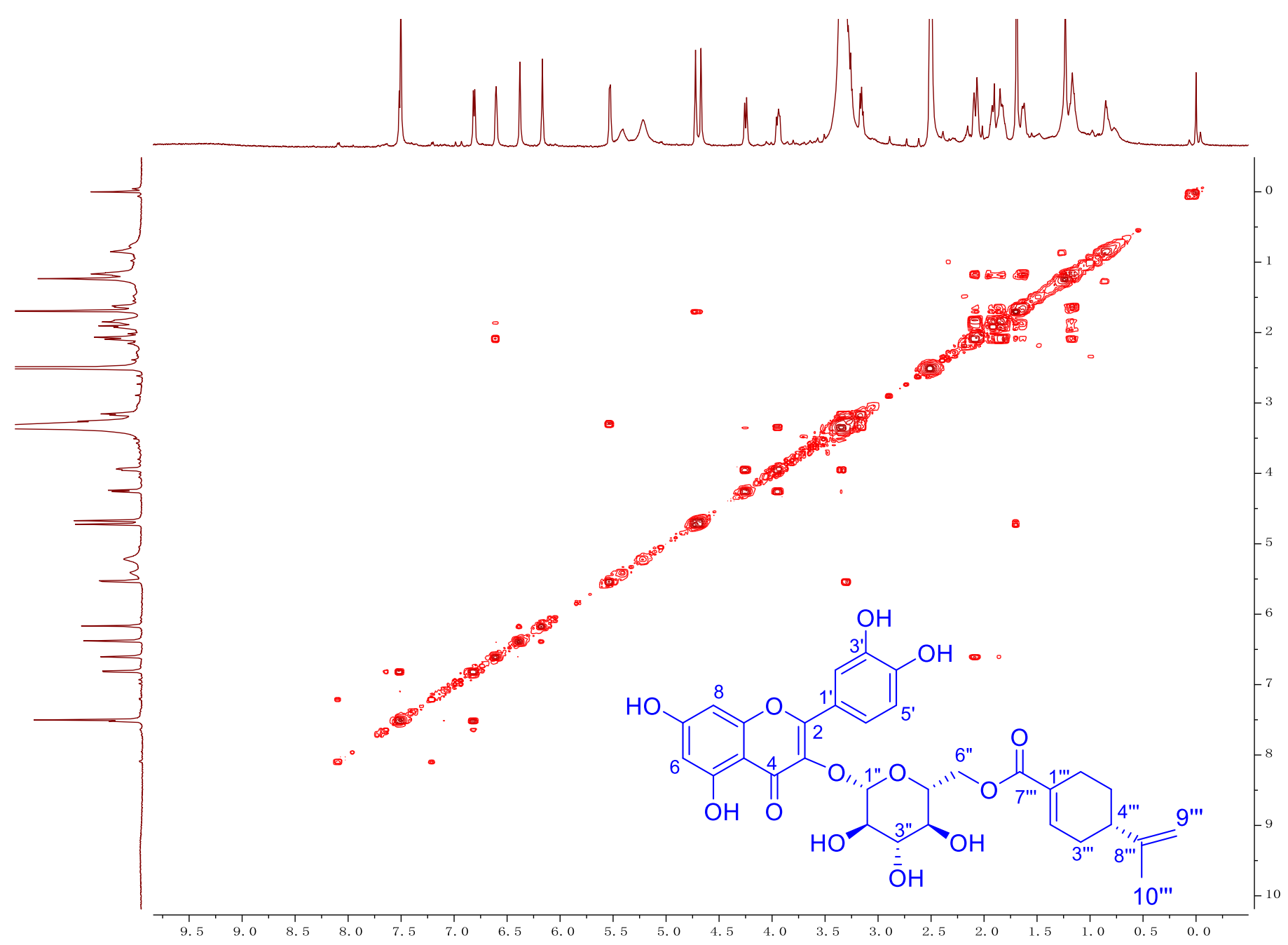

Figure S35. COSY spectrum of the new compound 6 


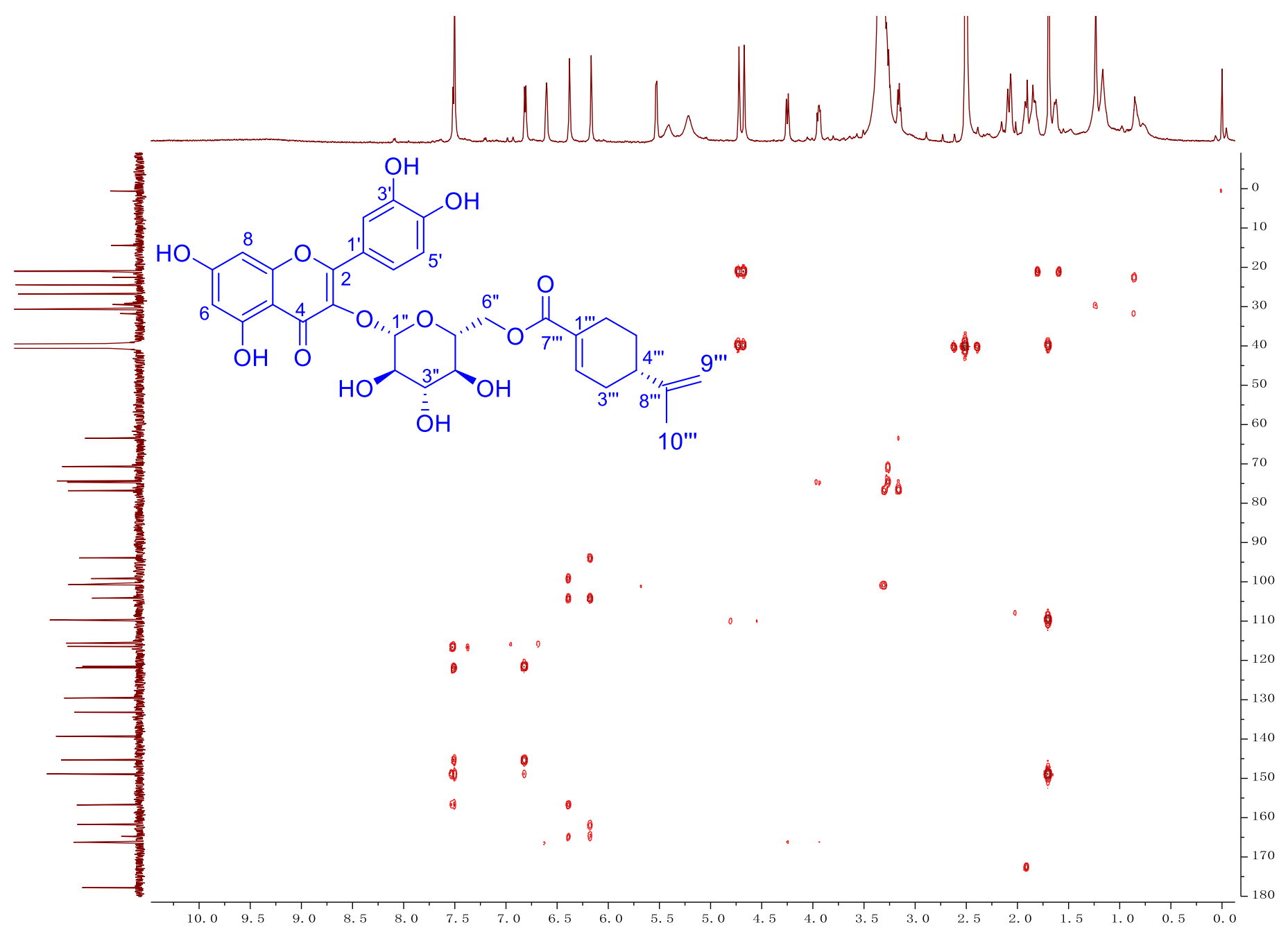

Figure S36. HMBC spectrum of the new compound 6 


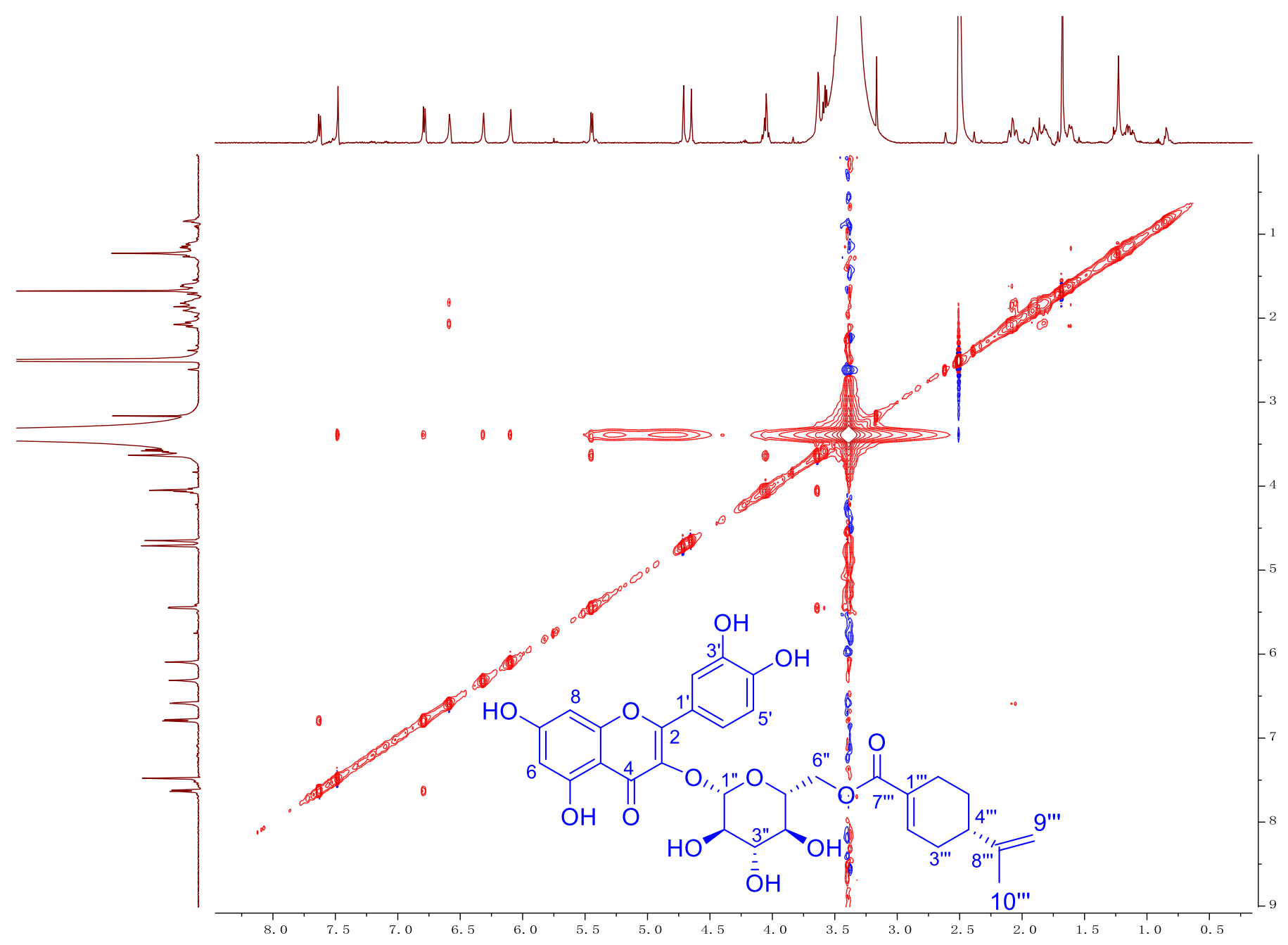

Figure S37. NOESY spectrum of the new compound 6 


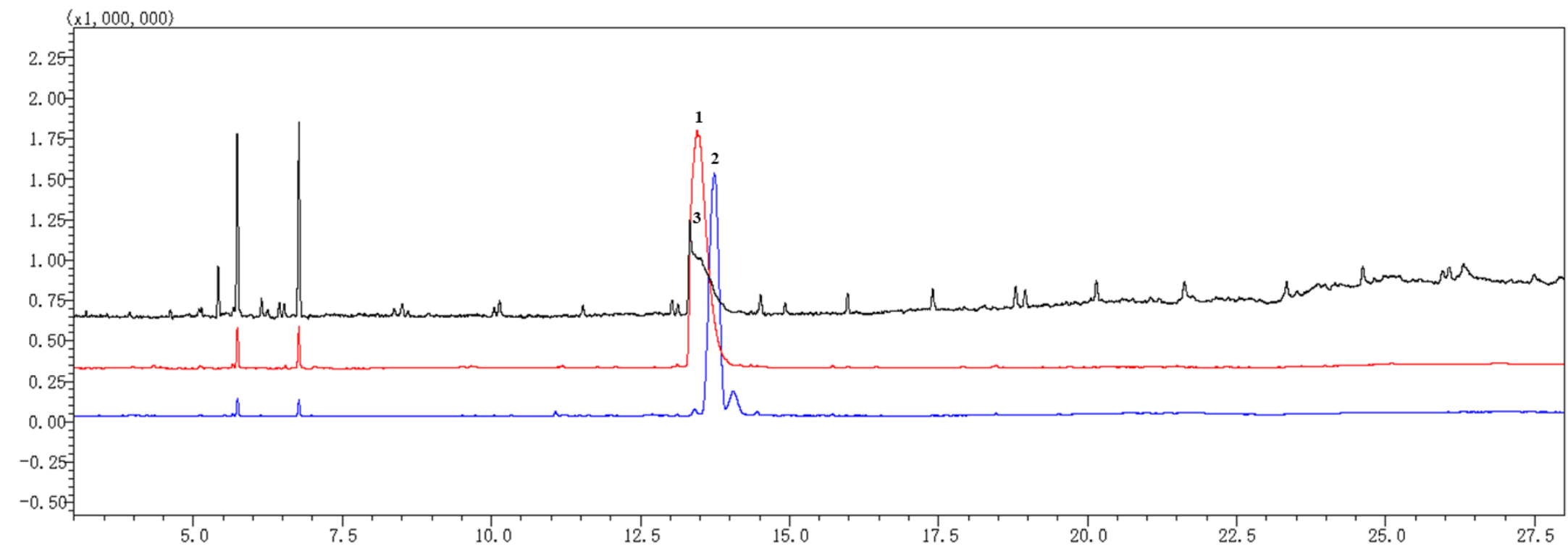

Figure S38. GC analysis of derivatives of standard D-glucose, L-glucose and sugar residue derivative of compound 6

Peak 1: derivative of standard D-glucose retention time $=13.45$ min; Peak 2: derivative of standard L-glucose retention time $=13.74$ min; Peak 3: sugar residue derivative of compound 6 retention time $=13.33 \mathrm{~min}$; Red line: derivative of standard D-glucose; Blue line: derivative of standard L-glucose; Black line: sugar residue derivative of compound $\mathbf{6}$. 


\section{Qualitative Analysis Report}

Data Filename

Sample Type

Instrument Name

Acq Method

IRM Calibration Status

Comment

Sample Group

\section{Info.}

$\begin{array}{lll}\text { N-MS-97-NEG.d } & \text { Sample Name } & \text { Sample4 } \\ \text { Sample } & \text { Position } & \text { P1-A4 } \\ \text { Instrument } 1 & \text { User Name } & \\ \text { default-20170301-neg.m } & \text { Acquired Time } & \text { 3/20/2019 3:55:34 PM } \\ \text { Success } & \text { DA Method } & \text { default_Analysis.m }\end{array}$

DA Method

User Spectra

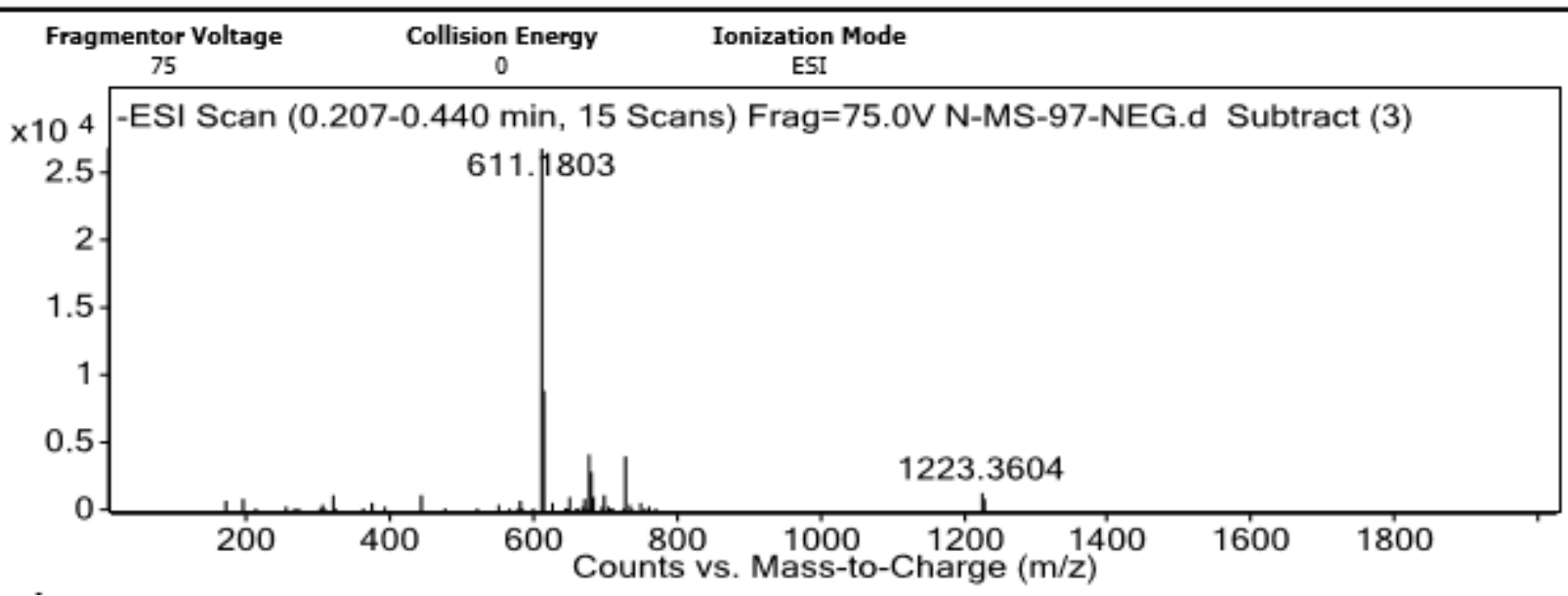

Figure S39. HRESI-MS spectrum of the new compound 7 


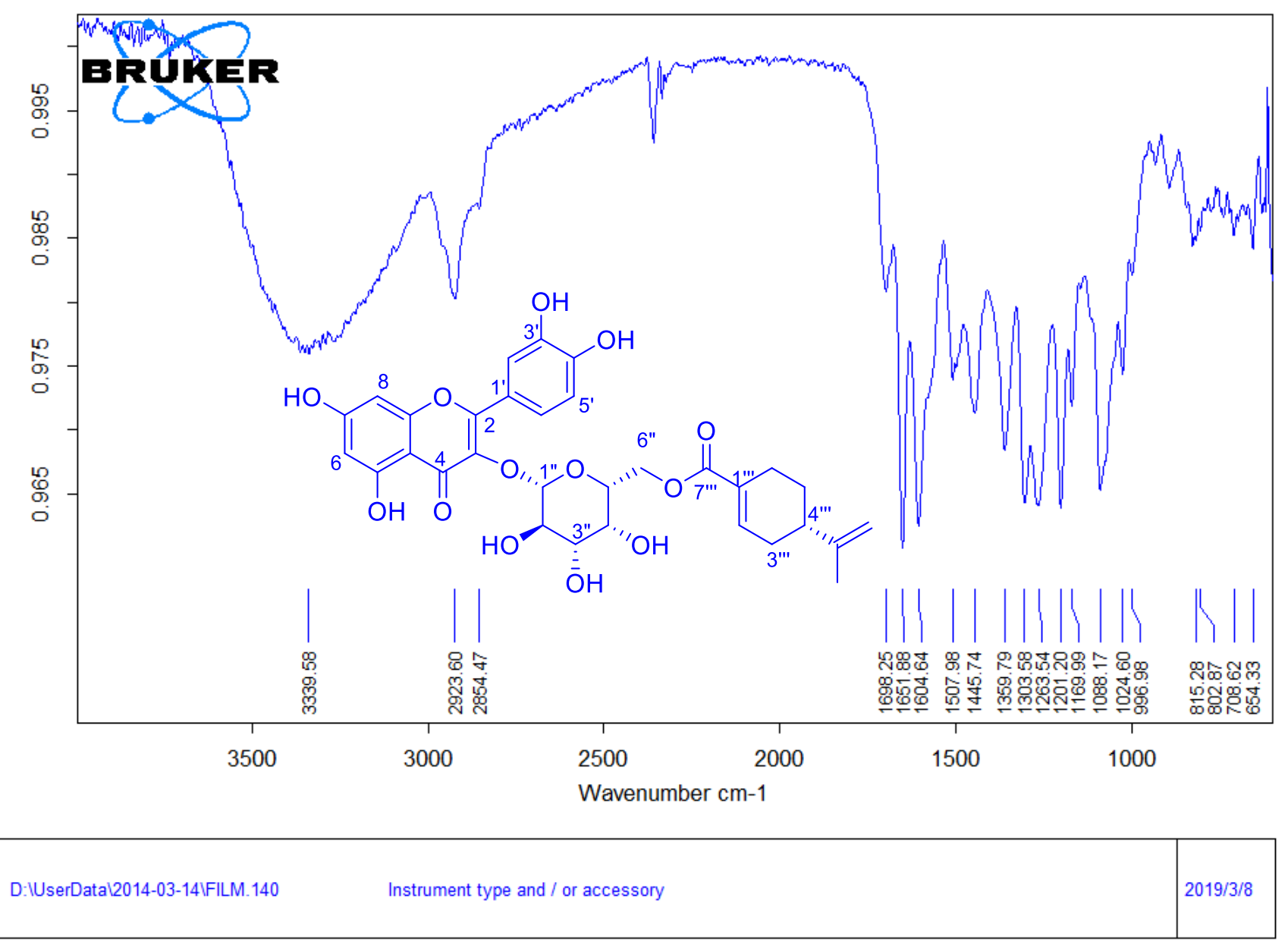

Page 1/1

Figure S40. IR spectrum of the new compound 7 


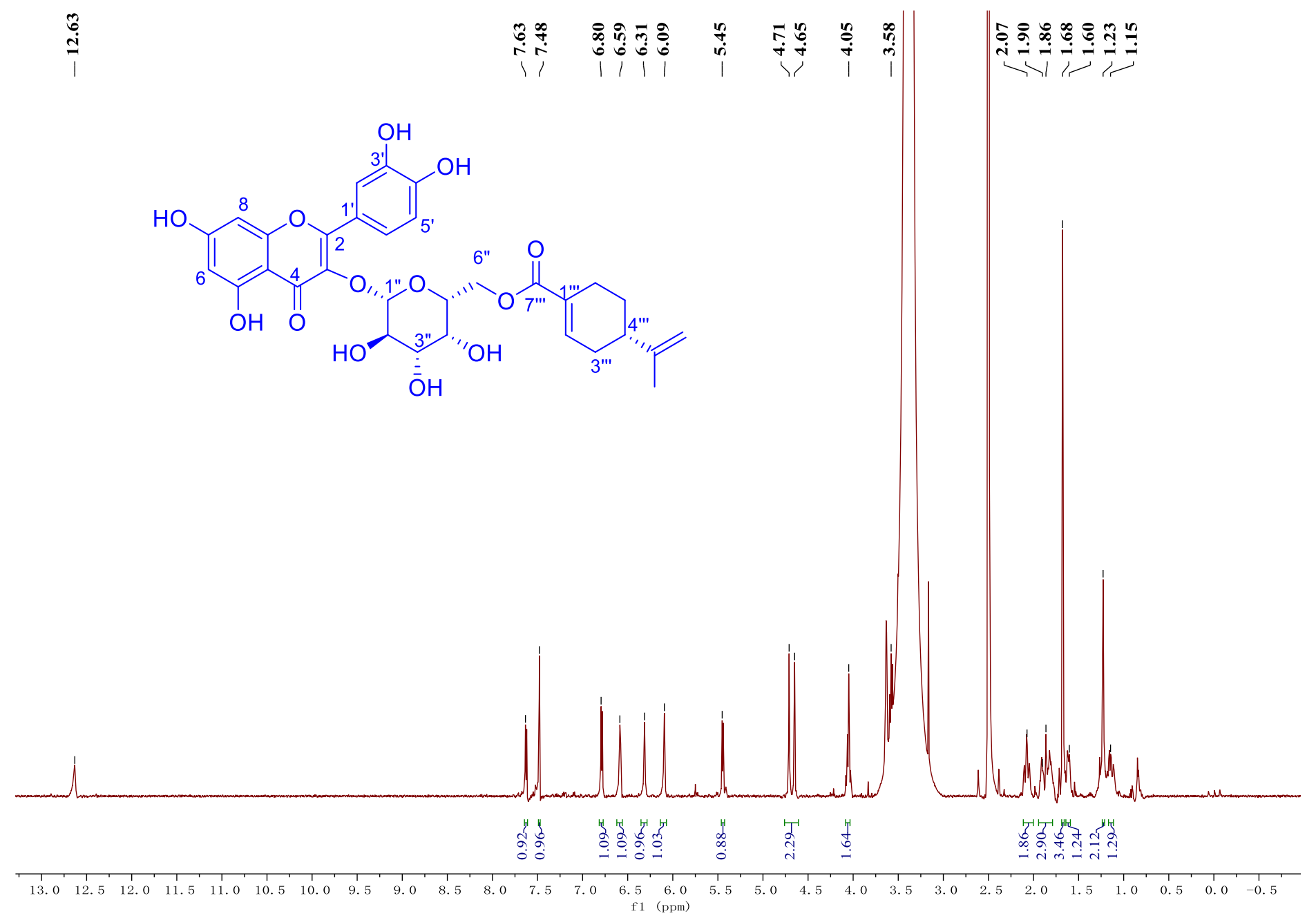

Figure S41. ${ }^{1} \mathrm{H}$ NMR $\left(600 \mathrm{MHz}, \mathrm{DMSO}-d_{6}\right)$ spectrum of the new compound 7 


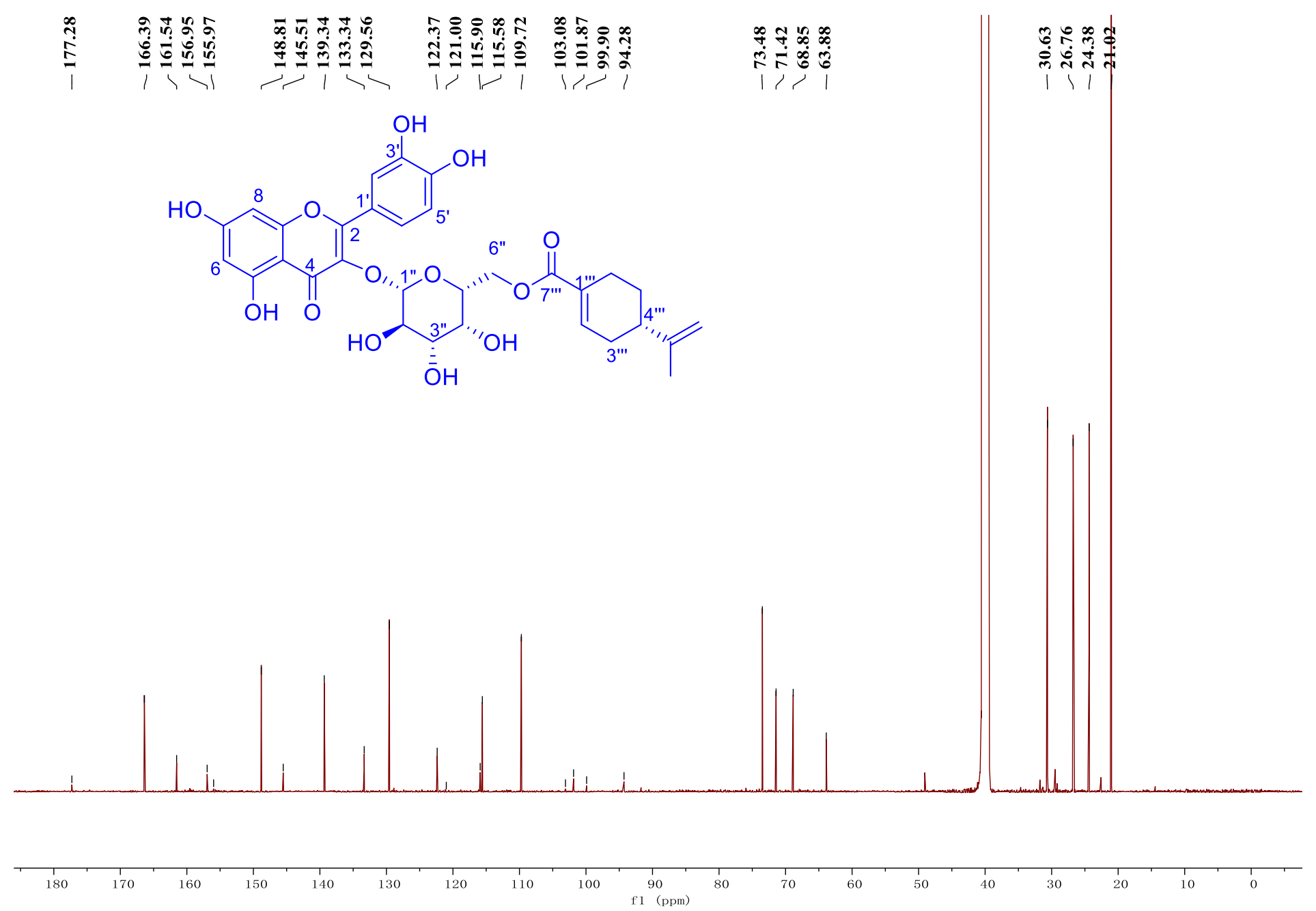

Figure S42. ${ }^{13} \mathrm{C}$ NMR (150 MHz, DMSO- $\left.d_{6}\right)$ spectrum of the new compound 7 

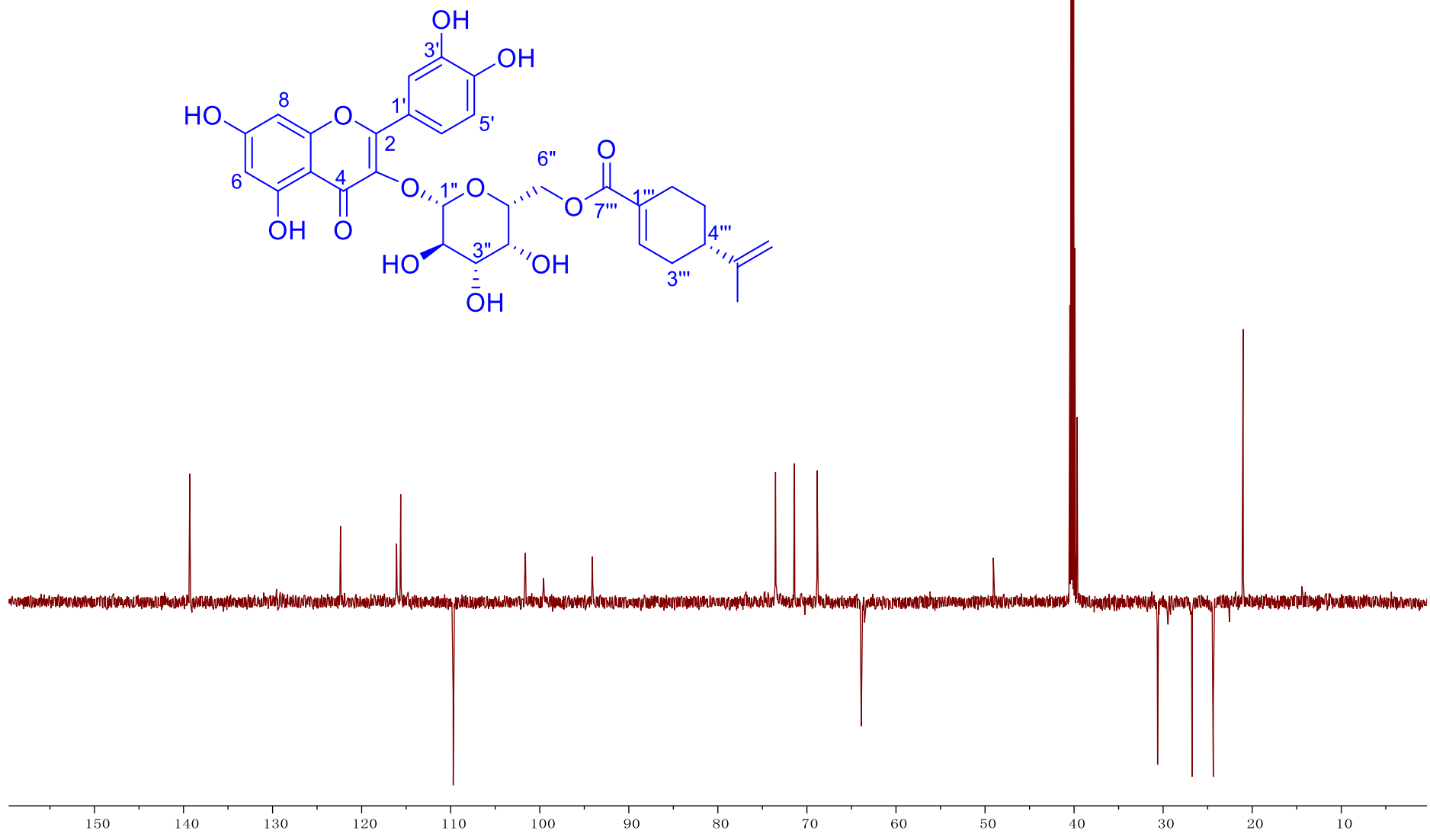

Figure S43. DEPT (150 MHz, DMSO- $d_{6}$ ) spectrum of the new compound 7 


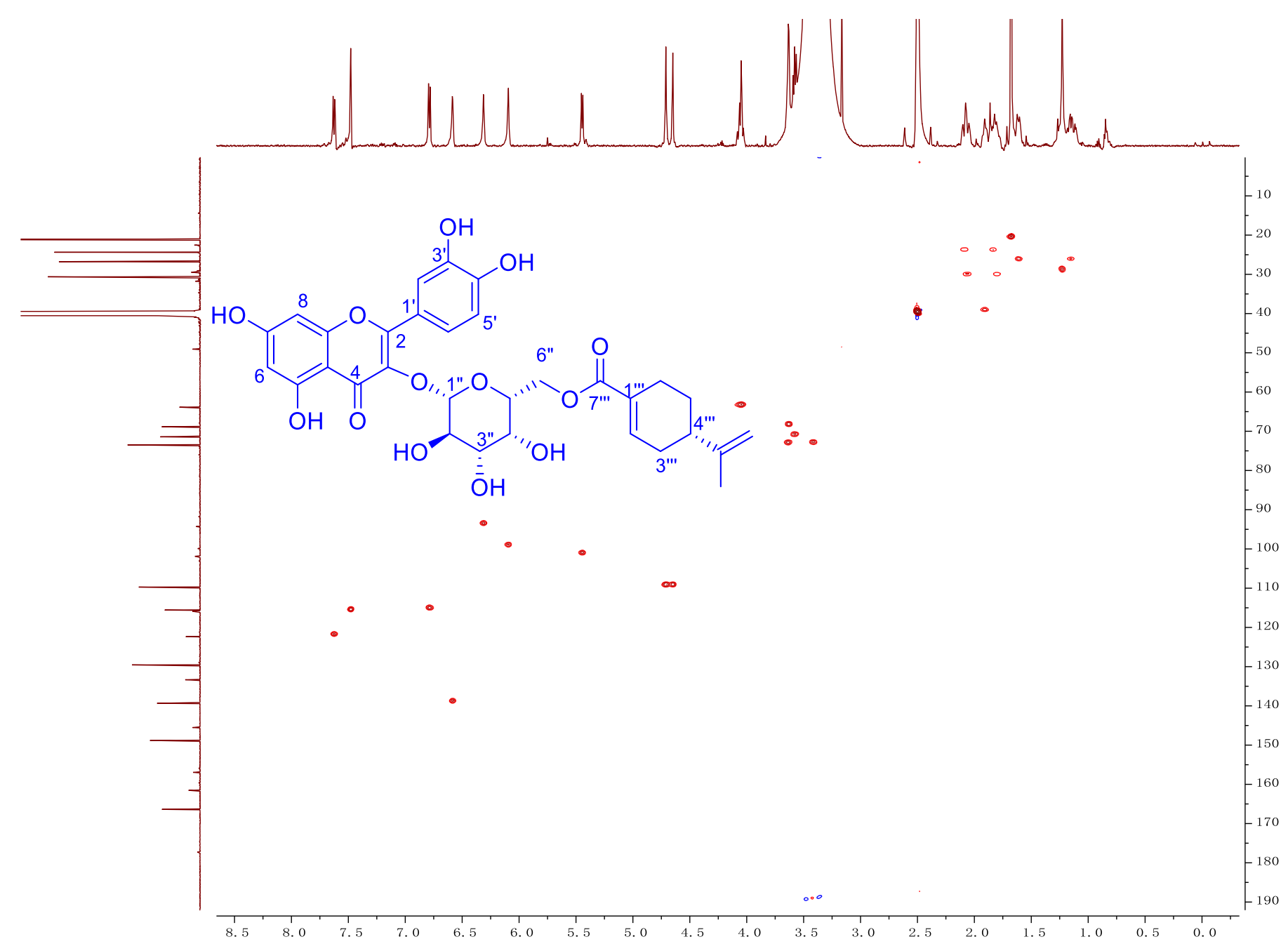

Figure S44. HSQC spectrum of the new compound 7 


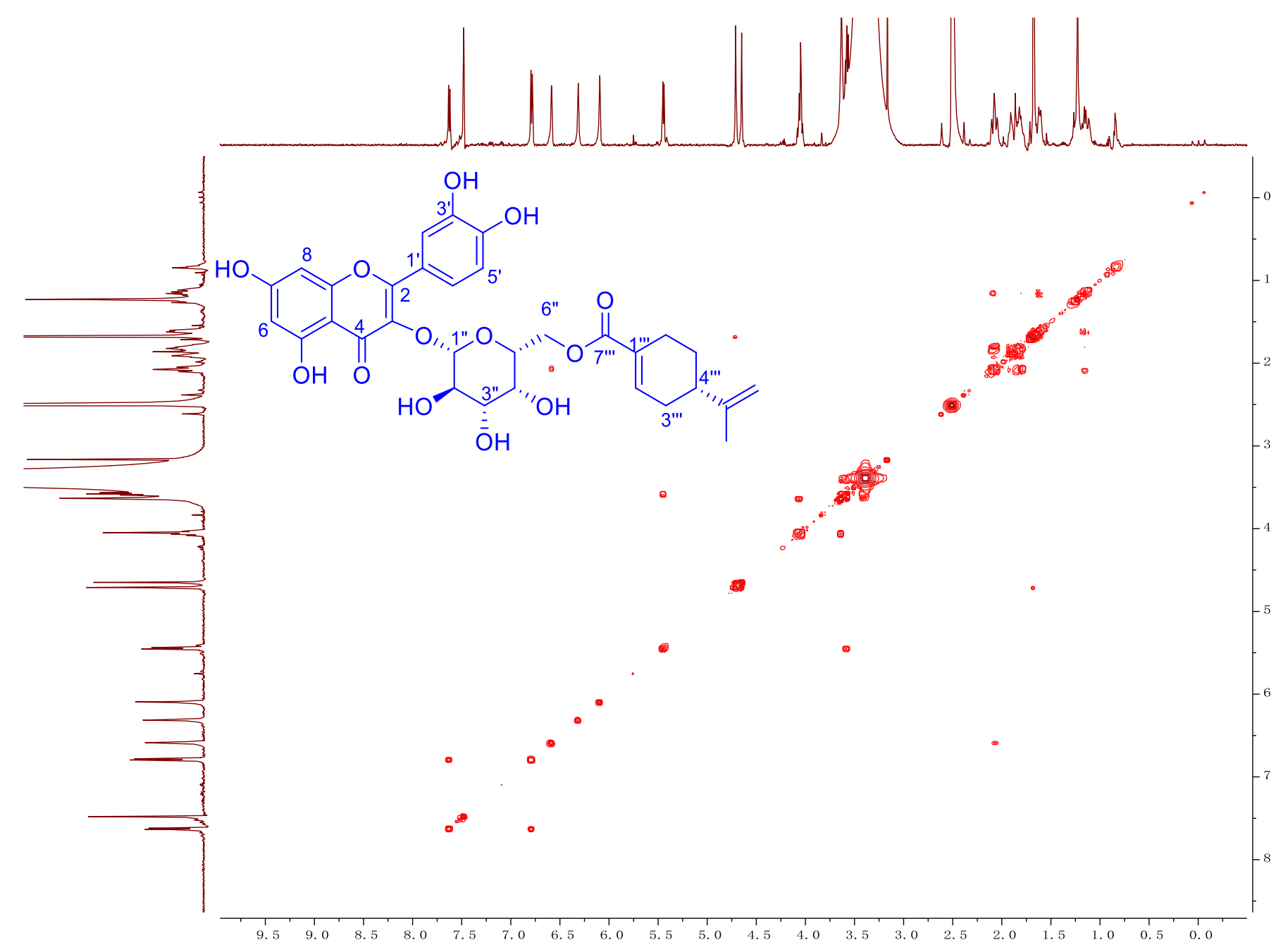

Figure S45. COSY spectrum of the new compound 7 


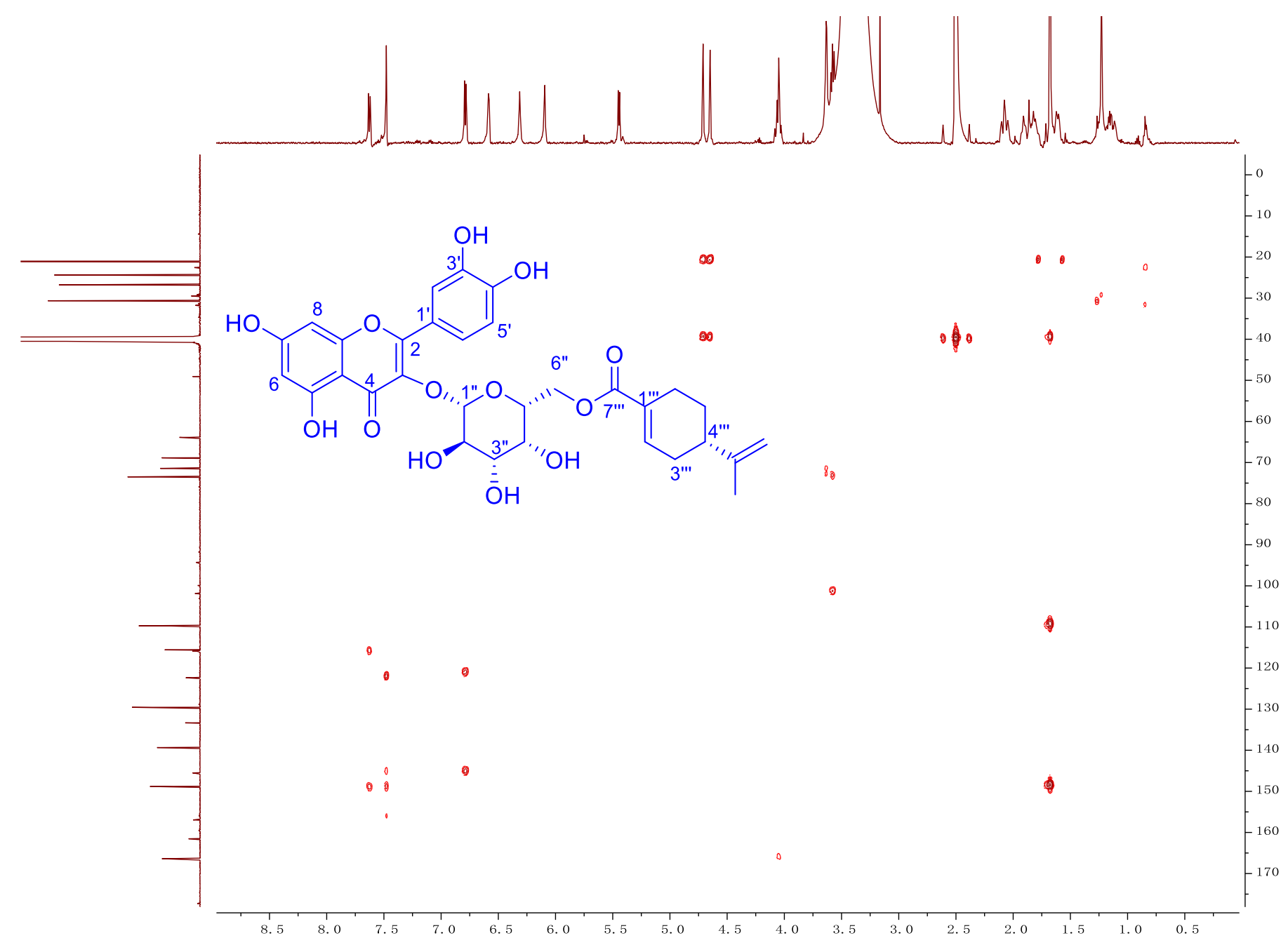

Figure S46. HMBC spectrum of the new compound 7 


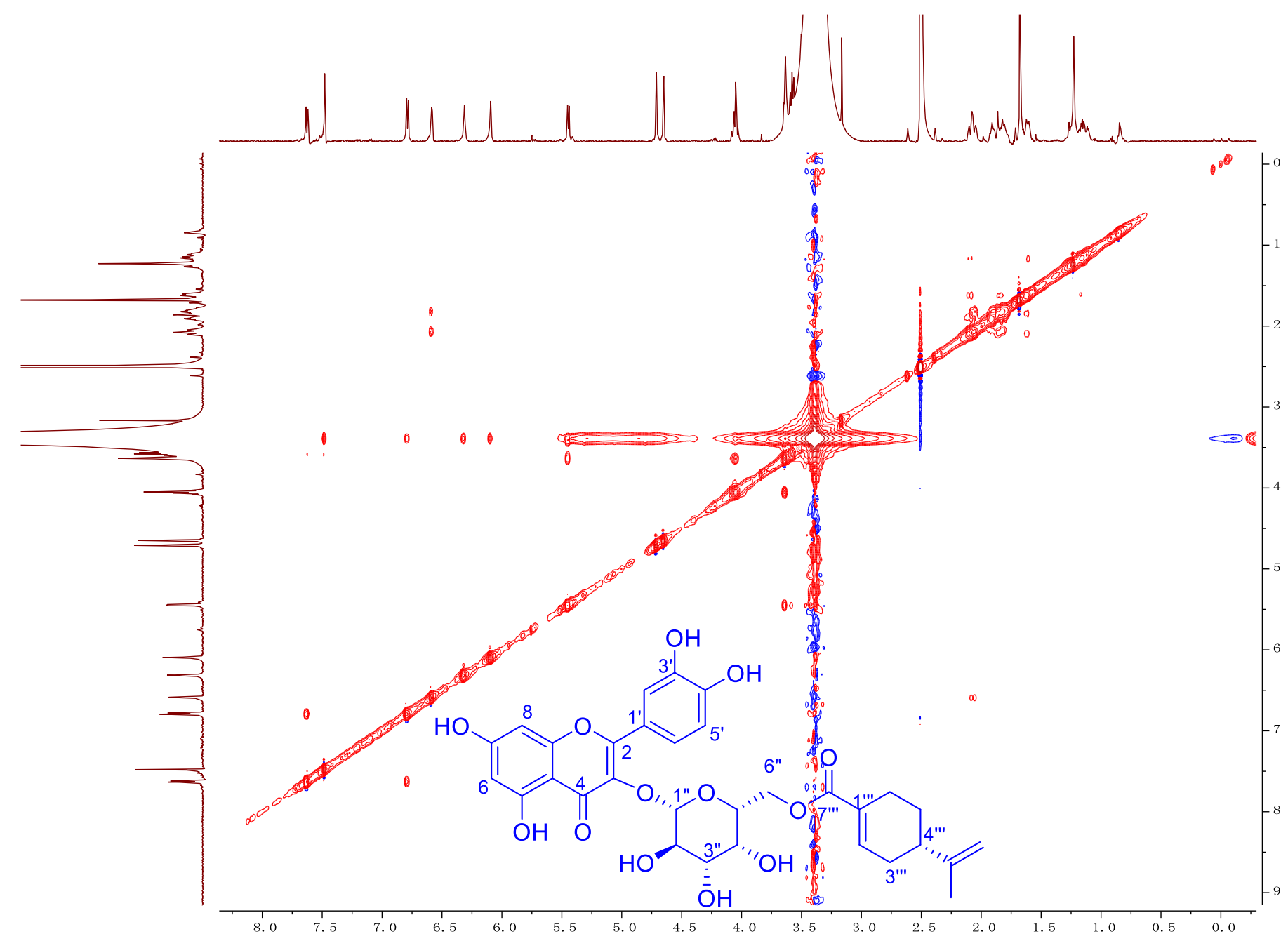

Figure S47. NOESY spectrum of the new compound 7 


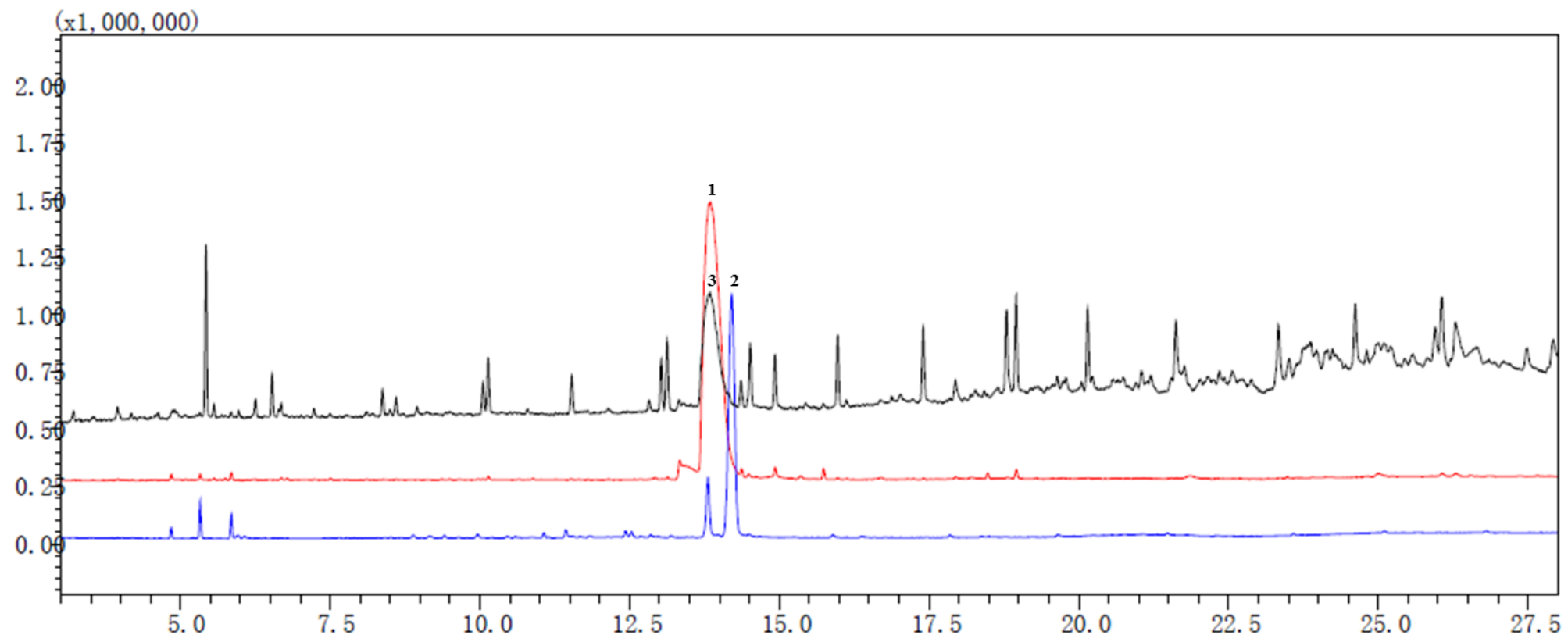

Figure S48. GC analysis of derivatives of standard D-galactose, L-galactose and sugar residue derivative of compound 7 Peak 1: derivative of standard D-galactose retention time $=13.84 \mathrm{~min}$; Peak 2: derivative of standard L-galactose retention time $=14.21$ min; Peak 3: sugar residue derivative of compound 7 retention time $=13.84$ min; Red line: derivative of standard D-galactose; Blue line: derivative of standard L-galactose; Black line: sugar residue derivative of compound 7. 


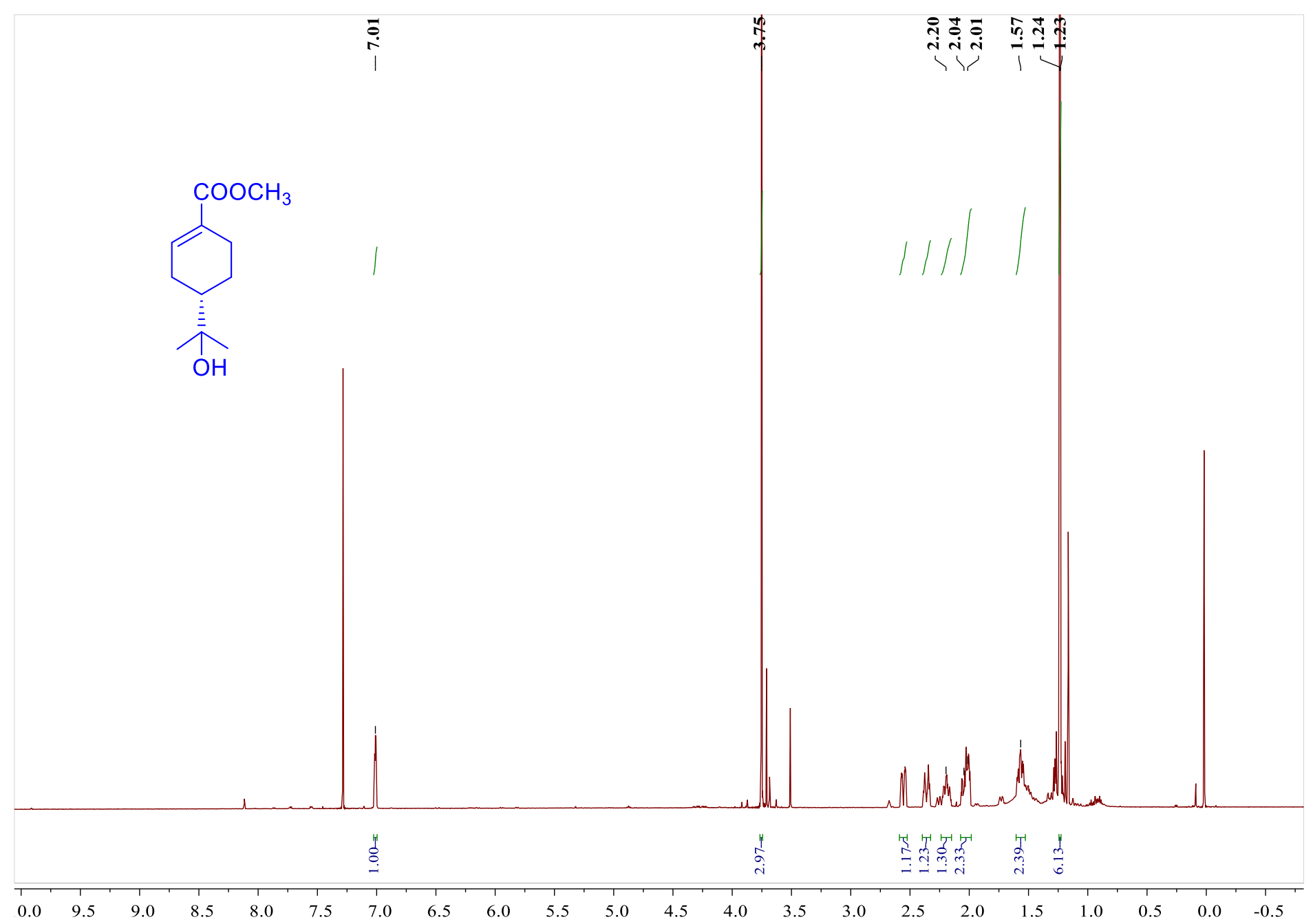

Figure S49. ${ }^{1} \mathrm{H}$ NMR $\left(600 \mathrm{MHz}, \mathrm{CDCl}_{3}\right)$ spectrum of compound $\mathbf{1 b}$ 


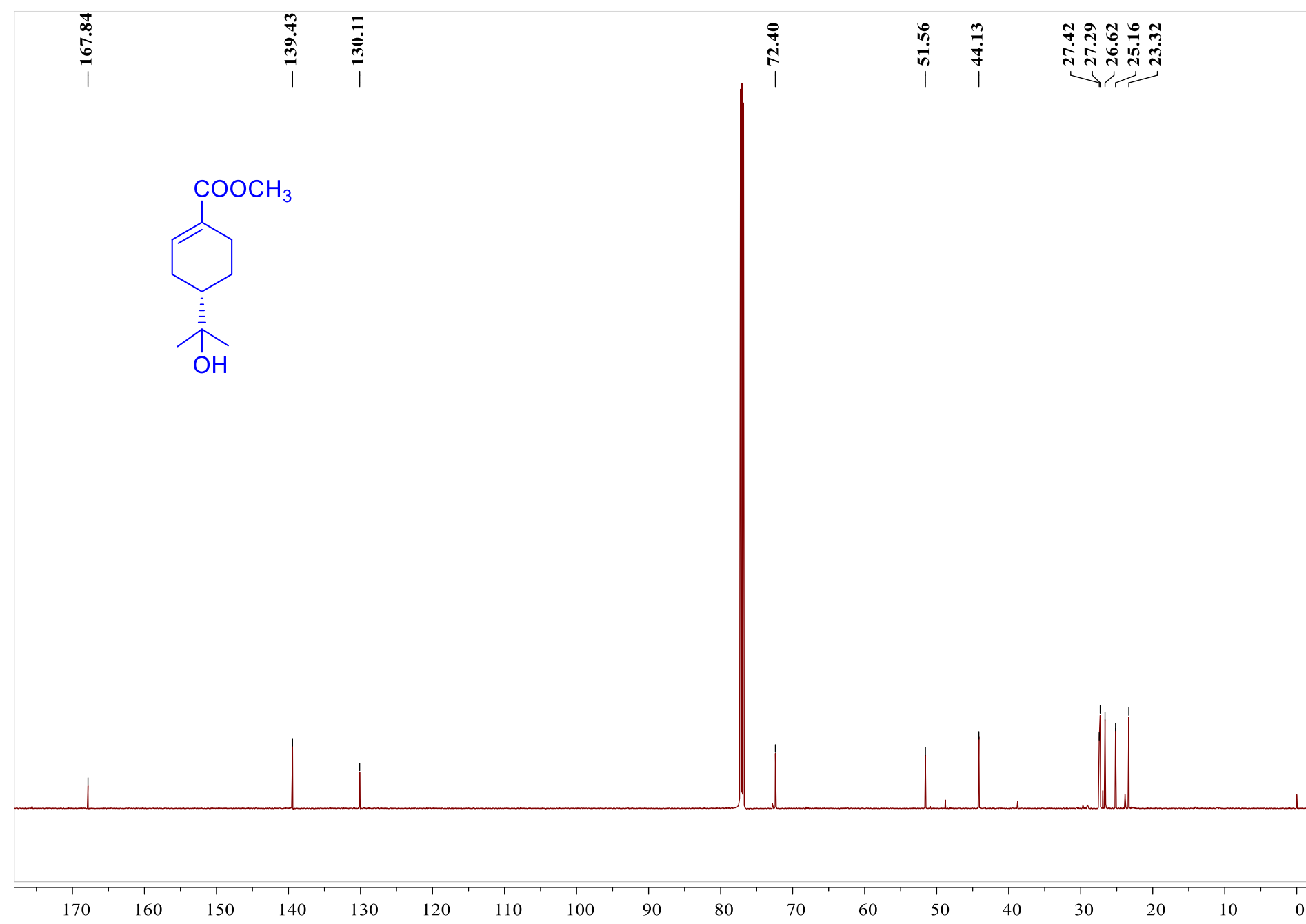

Figure S50. ${ }^{13} \mathrm{C}$ NMR $\left(150 \mathrm{MHz}, \mathrm{CDCl}_{3}\right)$ spectrum of compound $\mathbf{1 b}$ 


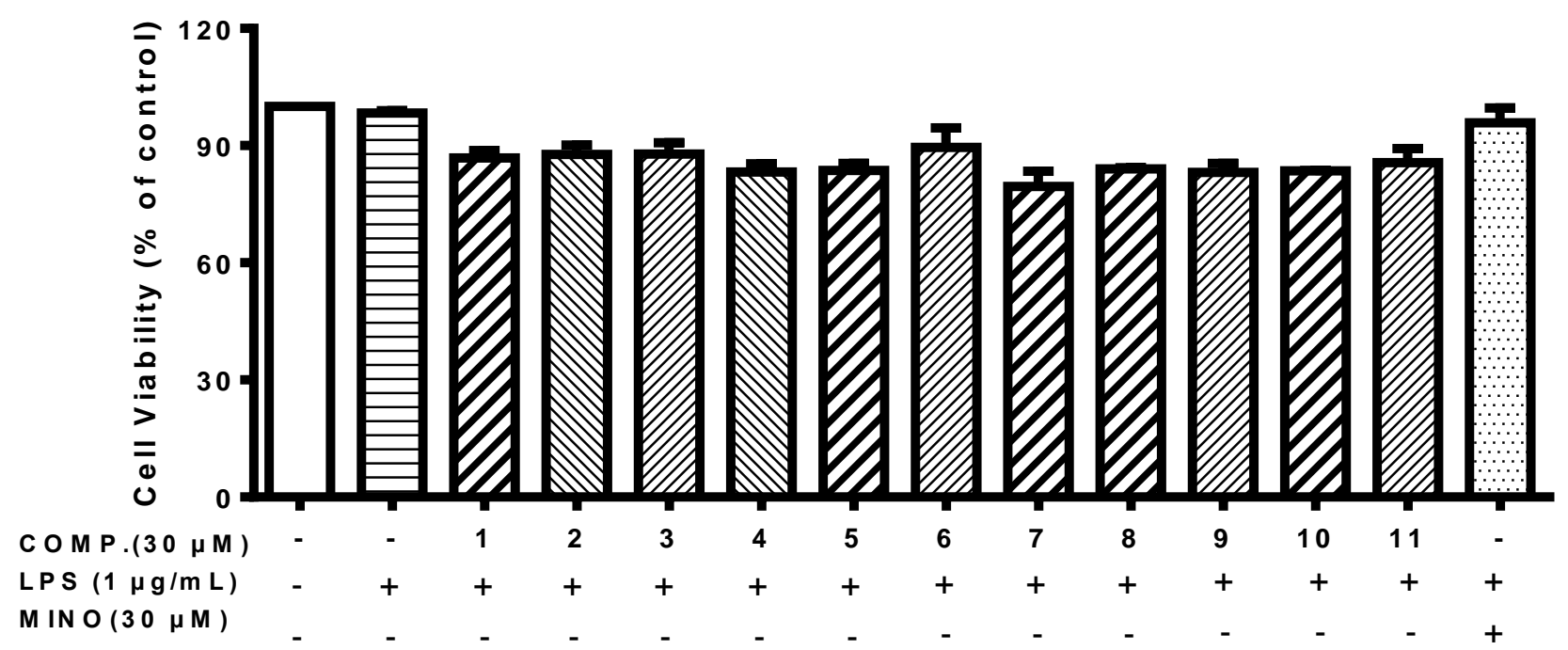

Figure S51. Effect of compounds 1-11 on cell viability of RAW 264.7 macrophages with LPS stimulation.

RAW 264.7 cells were plated at $1 \times 10^{4}$ cells per well in 96-well-plates and incubated for $12 \mathrm{~h}$, then treated with compounds 1-11 (30 $\mu \mathrm{M})$ and lipopolysaccharides (LPS, $1 \mu \mathrm{g} / \mathrm{mL})$ for $24 \mathrm{~h}$. After that MTT $(20 \mu \mathrm{L}, 5 \mathrm{mg} / \mathrm{mL})$ was added and incubated for additional $4 \mathrm{~h}$. Then the supernatant was removed and dimethylsulfoxide (DMSO, $150 \mu \mathrm{L}$ ) was added for solubilization. The absorbance was read at $570 \mathrm{~nm}$. 
Table S1. DPPH free radical scavenging activity of compounds 12-28

\begin{tabular}{cc}
\hline \hline No. & $\mathrm{IC}_{50}(\mu \mathrm{M})$ \\
\hline $\mathbf{1 2}$ & $>200$ \\
$\mathbf{1 3}$ & $>200$ \\
$\mathbf{1 4}$ & $>200$ \\
$\mathbf{1 5}$ & $>200$ \\
$\mathbf{1 6}$ & $>200$ \\
$\mathbf{1 7}$ & $>200$ \\
$\mathbf{1 8}$ & $>200$ \\
$\mathbf{1 9}$ & $>200$ \\
$\mathbf{2 0}$ & $>200$ \\
$\mathbf{2 1}$ & $>200$ \\
$\mathbf{2 2}$ & $>200$ \\
$\mathbf{2 3}$ & $>200$ \\
$\mathbf{2 4}$ & $>200$ \\
$\mathbf{2 5}$ & $>200$ \\
$\mathbf{2 6}$ & $>200$ \\
$\mathbf{2 7}$ & $>200$ \\
$\mathbf{2 8}$ & $>200$
\end{tabular}

Ascorbic acid ${ }^{a} \quad 108.60 \pm 5.63$

${ }^{a}$ Positive control substance 
Table S2. ROS scavenging capacity of compounds 1-11 in RAW 264.7 macrophages with LPS stimulation

\begin{tabular}{cc}
\hline \hline No. & scavenging capacity $(\%)$ \\
\hline $\mathbf{1}$ & $19.83 \pm 0.15$ \\
$\mathbf{2}$ & $22.38 \pm 1.82$ \\
$\mathbf{3}$ & $11.02 \pm 1.89$ \\
$\mathbf{4}$ & $10.70 \pm 2.74$ \\
$\mathbf{5}$ & $31.53 \pm 2.81$ \\
$\mathbf{6}$ & $35.98 \pm 2.78$ \\
$\mathbf{7}$ & $35.81 \pm 3.27$ \\
$\mathbf{8}$ & $30.57 \pm 3.36$ \\
$\mathbf{9}$ & $35.85 \pm 1.73$ \\
$\mathbf{1 0}$ & $37.69 \pm 2.83$ \\
$\mathbf{1 1}$ & $37.01 \pm 3.01$ \\
MINO $^{a}$ & $37.25 \pm 3.49$
\end{tabular}

${ }^{a}$ Positive control substance 


\section{Extraction and Isolation of compounds 12-28}

The petroleum ether extract (160.0g) was subjected to silica gel column chromatography with petroleum ether/ethyl acetate (100:1, $50: 1 ; 20: 1 ; 10: 1,5: 1 ; 1: 1 \mathrm{v} / \mathrm{v})$ to produce six subfractions (Fr. P.1-6). Fraction P.2 (20.7 g) was subjected to a silica gel column (petroleum ether/ethyl acetate 80:1, v/v) to yield three subfractions (P.2.1-2.3). Subfraction P.2.2 was separated by Sephadex LH-20 column chromatography $\left(\mathrm{CH}_{2} \mathrm{Cl}_{2} / \mathrm{MeOH} 1: 1\right.$, v/v), and they purified by ODS column with $\left(\mathrm{MeOH} / \mathrm{H}_{2} \mathrm{O} 95 \%\right.$, v/v) and semi-preparative HPLC $\left(95 \% \mathrm{ACN} / \mathrm{H}_{2} \mathrm{O}, \mathrm{v} / \mathrm{v}\right)$ to yield compounds $12(17.0 \mathrm{mg}), \mathbf{1 3}(13.2 \mathrm{mg}), \mathbf{1 4}(13.3 \mathrm{mg})$ and 15 (250.0 mg). Similarly, fraction P.3 (25.2 g) was chromatographed over a silica gel column (petroleum ether/ethyl acetate 50:1, v/v) to yield three subfractions (P.3.1-3.3). Each subfraction was subjected to Sephadex LH-20 column chromatography $\left(\mathrm{CH}_{2} \mathrm{Cl}_{2} / \mathrm{MeOH}\right.$ 1:1, v/v) individually, and further purified by semi-preparative $\mathrm{HPLC}\left(93 \% \mathrm{ACN} / \mathrm{H}_{2} \mathrm{O}\right.$, v/v) to yield $16(13.1 \mathrm{mg}), \mathbf{1 7}(13.5 \mathrm{mg}), \mathbf{1 8}$ (13.9 mg) and 19 (15.0 mg), respectively. Fraction P.4 (30.0 g) was put on a silica gel column (petroleum ether/ethyl acetate 30:1, v/v) to yield three subfractions (P.4.1-4.3). Subfraction P.4.1 was sequentially separated over a silica gel column (petroleum ether/ethyl acetate 40:1, v/v) and Sephadex LH-20 column $\left(\mathrm{CH}_{2} \mathrm{Cl}_{2} / \mathrm{MeOH}\right.$ 1:1, v/v), and further purified by semi-preparative HPLC (95\% $\mathrm{MeOH} / \mathrm{H}_{2} \mathrm{O}$, v/v) to yield compounds 20 (10.0 mg), 21 (18.1 mg) $22(70.6 \mathrm{mg}), 23(16.3 \mathrm{mg})$ and 24 (19.8 mg). Subfraction P.4.2 was subjected to Sephadex LH-20 column chromatography $\left(\mathrm{CH}_{2} \mathrm{Cl}_{2} / \mathrm{MeOH} 1: 1, \mathrm{v} / \mathrm{v}\right)$, and then purified by semi-preparative HPLC (93\% $\mathrm{MeOH} / \mathrm{H}_{2} \mathrm{O}$, v/v) to yield 25 (15.0 mg). Similarly, subfraction P.4.3 was put on a silica gel column (petroleum ether/ethyl acetate 40:1, v/v), and then separated over an ODS column (95\% $\mathrm{MeOH} / \mathrm{H}_{2} \mathrm{O}$, v/v) to afford compounds 26 (12.3 mg), 27 (10.8 mg), 28 (10.0 mg). 